\title{
NOUVEAUX ÉCLAIRCISSEMENTS SUR LA VIE ET L'EEUVRE D'ANTOINE GALLAND (1646-1715)
}

\author{
SA SMYRNE ANCIENNE ET MODERNE: HISTOIRE, CONTENU ET \\ ÉTUDE DE L'AUTOGRAPHE ${ }^{1}$
}

PAR

\author{
FRÉDÉRIC BAUDEN*
}

[...] je suis éloigné de la France que je regarde comme mon centre [...]. Antoine Galland, Lettre adressée à Jacob Spon de Constantinople en octobre $1682^{2}$.

* Professeur à l'Université de Liège, Langue arabe et études islamiques. 7, place du 20 Août, Bât. A1. B-4000, Liège (Belgique).

${ }^{1}$ Cet article reprend et développe la matière d'une communication présentée au XIX ${ }^{\mathrm{e}}$ Congrès de l'Union Européenne des Arabisants et Islamisants, qui s'est tenu à l'Université de Halle en septembre 1998. L'importance de la Smyrne ancienne et moderne pour les études ottomanes fera l'objet d'une autre étude.

2 Conservée à la BnF, Cabinet des Médailles, archives, dossier de l'année 1682. Elle fut éditée par M. Abdel-Halim, Correspondance d'Antoine Galland [dorénavant Correspondance], pp. 158-66. Cette édition contient les lettres de Galland conservées à la BnF et celles qu'il envoya à son ami hollandais Gisbert Cuper, aujourd'hui préservées à la Bibliothèque de La Haye. Il faut désormais y ajouter d'autres lettres qui sont réapparues depuis lors ou qui avaient échappé à la vigilance du biographe de Galland: à la British Library, Londres (Sloane Papers, Dutch copies 130, ff. 5, 8, 10b; correspondance relative à des monnaies du cabinet de Louis XIV et datée de 1697-8), à la Bodleian Library, Oxford (ms. Smith 46; plusieurs lettres de Galland datant de 1676-7). V. F. Madan, A Summary Catalogue of Western Manuscripts in the Bodleian Library at Oxford. Volume III, p. $461\left(\mathrm{n}^{\circ} 15653\right)$.

Ajoutons enfin qu'un extrait d'une lettre écrite à Cuper, le 10 avril 1711, avait déjà été publié dans Lettres de critique, d'histoire, de littérature, etc écrites à divers savans de l'Europe, par feu Monsieur Gisbert Cuper [...] publiées sur les originaux par Monsieur de $B^{* *}$, pp. 98-100. Deux lettres adressées par Cuper à Galland sont, elles, publiées aux pp. 254-67. D'autres informations importantes sur Galland figurent également dans ce livre qui n'avait pas été exploité par Abdel-Halim. 


\section{RÉSUMÉ}

Bien avant d'être le génial inventeur des Mille et une Nuits, le chef-d'œuvre invisible, pour reprendre l'expression de G. May, Antoine Galland fut un voyageur qui arpenta le Levant et ses principales échelles pendant près de quinze ans. En diariste convaincu, il nous a légué plusieurs témoignages de cette période de sa vie qui couvre l'intervalle allant de 24 à 42 ans. Il s'agit d'une partie de son Journal (années 1672-1673), dans lequel il relate son séjour à Constantinople au cours du premier voyage qu'il entreprit, et de son récit de voyage intitulé Voyage fait en Levant (années 1679-1680), qui décrit les événements survenus durant sa troisième et dernière pérégrination en Orient. Ceux-ci étaient connus de longue date et furent d'ailleurs exploités par son biographe, M. AbdelHalim, tandis que d'autres étaient attestés mais ont disparu. C'est justement l'un de ses textes relatifs à la période en cause (la Smyrne ancienne et moderne datant de 1678, autrement dit son second voyage au Levant) que nous avons retrouvé et qui n'a, jusqu'à présent, fait l'objet d'aucune étude exhaustive. Nous entendons l'analyser dans cet article en retraçant l'histoire du manuscrit qui le contient, tout en ayant recours à d'autres manuscrits autographes de Galland et à des sources inédites. Une importante partie est aussi consacrée à l'étude du contenu, afin de démontrer que la description que notre auteur donne de Smyrne à cette époque peut être considérée comme la plus complète qui soit connue à ce jour. Enfin, ce texte contient d'importantes données personnelles qui permettent de combler des lacunes dans la bio-bibliographie de cet homme qui devait passer à la postérité.

Mots-clés: Galland, relations de voyages, XVII ${ }^{\mathrm{e}}$ s., Smyrne/Izmir, orientalisme

\section{ABSTRACT}

Antoine Galland paced the Levant and its most important scales during almost 15 years before he came to be known as the inspired inventor of the Thousand and One Nights, to borrow G. May's words. He was also a convinced diarist, and he left us several accounts concerning this period of his life which began at the age of 24 and ended with his 42 years. These are one part only of his Journal (years 1672-1673), in which he relates his sojourn in Constantinople during his first travel, and his relation entitled Voyage fait en Levant (years 1679-1680) that describes the events which occurred during his third and last peregrination in the Orient. These relations are known since a long time and moreover were turned into account by his biograph, M. Abdel-Halim, while others were attested but considered as lost. It is a text of this second category, which is connected to the period under discussion (Smyrne ancienne et moderne going back to 1678, 
in other words during his second travel in the Levant), that we have rediscovered and that had not been studied exhaustively till now. Our purpose in this paper is to analyze it by reconstructing the history of the manuscript which preserves it, and also resorting to other autograph manuscripts and unpublished sources. Importance is given to the study of its content too in order to demonstrate that the description of Smyrna given by our author may be considered as the most complete one in comparison with contemporaneous known sources. Finally, this text contains important personal data which give us the opportunity to fill in gaps prevailing in the bio-bibliography of this scholar who had to achieve an eternal fame.

Key words: Galland - travel relations - 17th c. - Smyrna/Izmir orientalism

\section{A. INTRODUCTION}

Le nom d'Antoine Galland fait surgir immanquablement dans l'esprit du lecteur l'idée des Mille et une Nuits. On sait pourtant depuis peu que pour le principal intéressé, ce texte, à la traduction duquel il consacrait ses heures perdues, ne représentait rien moins qu'un ouvrage de fariboles divertissantes. La gloire que celui-ci lui apporta de son vivant même avait pour lui un goût amer, d'autant plus quand il songeait à ses travaux personnels, véritables sommes d'érudition. Parmi ceux-ci, on compte notamment plusieurs relations de voyages, dont la plupart sont aujourd'hui considérées comme perdues. Comme pour la majeure partie de ce qu'il écrivit, il fit preuve de sérieux, de probité et se démarqua clairement de ses contemporains car, à ses yeux, la relation de voyage devait être bien plus qu'un simple compte rendu du voyage, farci d'anecdotes plus fausses les unes que les autres. Dès lors, on comprend mieux, en lisant les rares exemples de ses relations écrits de sa main et préservés, pourquoi celles-ci annoncent ce que l'on attendra d'un voyageur au siècle suivant. Pour en revenir aux relations elles-mêmes, il est établi qu'elles furent rédigées dans un intervalle qui va de 1670 à 1688, autrement dit durant les trois voyages que Galland accomplit dans toute sa carrière et dont la durée totale, trajets terrestres et maritimes compris, fut de 179 mois ou 14 ans et 11 mois $^{3}$ :

${ }^{3}$ Les 20 années mentionnées par M. Abdel-Halim, Antoine Galland, p. 301, doivent être prises comme une estimation. 
1) Août 1670-début 1675. Le Marquis de Nointel, nommé ambassadeur de Louis XIV auprès de la Porte, a pour mission principale d'obtenir le renouvellement des capitulations. Galland, âgé de 24 ans, l'accompagne et lui sert de secrétaire, notamment pour la question qui oppose le pasteur Claude, d'une part, et Arnault et Nicole d'autre part. Nointel est en effet chargé de recueillir des attestations des églises d'Orient pour appuyer les thèses d'Arnault et Nicole. Galland fait office d'interprète grâce à sa connaissance du grec ancien et moderne, dit «vulgaire». Son rôle est aussi d'acquérir des médailles et des manuscrits pour le compte de l'ambassadeur, qui souhaite les envoyer à Paris pour enrichir la bibliothèque du Roi et celle de Colbert. Constantinople sera le lieu de sa résidence, mais il sera amené à voyager aussi à Andrinople, Smyrne, Alep, les îles de l'Archipel, Jérusalem. De ce séjour qui dura 56 mois environ, c'est-à-dire un peu plus de 4 ans et demi, nous n'avons gardé qu'un unique témoignage: le Journal des années 1672-1673, disponible dans une édition imprimée à la fin du XIX ${ }^{\mathrm{e}} \mathrm{s}^{4}$.

2) Octobre 1677-août 1678. Il repart pour un second périple qui doit le conduire à Smyrne. Cette fois, il est commissionné par Jean FoyVaillant et l'abbé Giraud pour y acquérir des médailles destinées à être vendues ou offertes au Cabinet des Médailles du Roi. Selon ses propres dires, ce voyage dura de dix à onze mois. Il est donc de retour à Paris vers la fin de l'été 1678.

Nous savions qu'il avait écrit un ouvrage intitulé Smyrne ancienne et moderne, qui aurait dû paraître de son vivant même. Toutefois, le projet échoua et le manuscrit disparut après sa mort. C'est ce texte, qui constitue la première des pièces contenues dans le manuscrit redécouvert, qui fait l'objet de cet article .

3) Septembre 1679-décembre 1688. Il quitte, pour la troisième et dernière fois, sa terre natale pour se rendre dans le Levant, en septembre 1679. Son employeur est désormais la toute nouvelle Compagnie du Levant. Celle-ci, désireuse de remercier Colbert, qui en fut l'instigateur, le

${ }^{4}$ Journal d'Antoine Galland pendant son séjour à Constantinople (1672-1673). Édition de Ch. Schéfer, 2 vol. Paris: Ernest Leroux, 1881.

${ }^{5}$ Une édition de ce texte est parue. V. Le Voyage à Smyrne: un manuscrit d'Antoine Galland (1678), contenant Smyrne ancienne et moderne et des extraits du Voyage fait en Levant. Avant-propos d'André Miquel, textes présentés, établis et annotés par Frédéric Bauden. Paris: Éditions Chandeigne (collection Magellane), 2000, 336 p. 
charge d'acquérir des médailles et des manuscrits pour la bibliothèque de ce dernier et celle du Roi. Son périple le fera passer par Cagliari, Malte, Milos, Smyrne, Khios, Mytilène, et enfin Constantinople où il résidera pendant cinq ans, sous la protection de l'ambassadeur de Guilleragues. À sa mort, en 1685, il se voit nommé Antiquaire du Roy et le voici qui reprend la route pour les îles de l'Archipel, Smyrne, Alexandrie, afin de découvrir des manuscrits et des médailles destinés à la Bibliothèque du Roi. C'est au cours d'un second passage par Smyrne qu'il manque de périr dans le terrible tremblement de terre qui réduisit la ville en cendres, en juillet 1688. C'en est trop: il a 42 ans. Excédé, il décide de rentrer à Paris. Ce voyage, qui est le dernier, dura 112 mois, autrement dit quelque 9 ans et 4 mois.

Seule une relation couvrant les deux premières années (1679-1680), sous la forme de lettres, nous a été conservée et est toujours inédite ${ }^{6}$.

\section{B. DESCRIPTION DU MS.}

Le manuscrit, conservé au département des manuscrits de la Bibliothèque Royale Albert I ${ }^{\text {er }}$ à Bruxelles, sous la cote II 5359, fut inventorié le 12 août 1912, après avoir été acquis pour le prix de 6 florins lors d'une vente des libraires Burgersdijck et Niermans de Leiden. Il tient en $196 \mathrm{ff}$. plus trois blancs en tête et deux en queue ${ }^{7}$. Chaque folio mesure en moyenne 220x164 mm. La reliure du manuscrit est en veau jaspé avec double encadrement de filets dorés sur les plats, le dos étant à nervures décoré de filets dorés et portant une étiquette rouge dont l'inscription est: Voyage de Galland. Contrairement à ce titre, le codex comporte en fait trois textes. Le $\mathrm{f}^{\circ} 1$, ajouté par une main postérieure, porte le continentur suivant:

1. Voyage de M. Antoine Galland antiquaire du Roi de france qui comprend la description \& l'Etat ancien \& moderne de Smyrne.

${ }^{6}$ Voyage fait en Levant. Bayerische Staatsbibliothek, Munich, cod. gall. 727 et 728 .

7 Il s'agit de la foliotation effectuée à un moment ou à un autre dans l'histoire du manuscrit, moment qu'il reste difficile à situer. Cette foliotation a pu intervenir au moment de la reliure ou de son acquisition par la Bibliothèque Royale. Outre celle-ci, il existe une pagination plus ancienne, contemporaine de la date de copie des textes, qui ne concerne que les deux premières pièces du codex sur les trois qu'il contient. Cette pagination sera mentionnée au moment de la description de chacun des textes. 
2. Etat présent des Iles de Samos, Nicarie, Patmos \& du Mont Athos, par Joseph Georgerine, Archeveque de Samos, traduit du grec vulgaire en François, par M. Antoine Galland antiquaire de S. M. T. C.

3. Relation de l'Ile de Fines, par le Père Rabiri (ou Rabier, jésuite) en 1679 .

À l'exception du texte 2, la description fournie dans cette table des matières ne peut servir de base pour l'identification des textes, comme nous allons le constater. Elle contient plusieurs approximations qui ont d'ailleurs induit en erreur l'auteur du catalogue de la Bibliothèque Royale dans lequel notre manuscrit est décrit $^{8}$. Nous en proposons une autre description que voici:

1) le premier texte, qui couvre les ff. 3 à 137 (ou les pages 1 à 255 selon la pagination contemporaine de la copie), est intitulé ( $\left.f^{\circ} 3\right)$, de la main de l'auteur même: Smyrne ancienne et moderne. Il y a annexé par la suite: par A. Galland Antiquaire et Interprete des Langues orientales. L'ensemble de ces inscriptions a été raturé au profit d'un autre titre, d'une main différente", que l'on trouve sur le folio en regard, c'est-à-dire le $\mathrm{f}^{\circ} 2^{\mathrm{v}}$ : Voyage de $\mathrm{Mr}$ Galland ${ }^{10}$ qui comprend la description et l'Etat ancien \& moderne de Smyrne ${ }^{11}$.

Le texte est autographe et Galland y a ajouté quelques croquis de sa main qui, dans certains cas, sont esquissés au sein du texte même, mais qui, dans d'autres, ont été dessinés sur des morceaux de papier collés dans le manuscrit au moyen de gouttes d'encre, raison pour laquelle certains de ces dessins rapportés ont pu être arrachés. Galland y faisant référence dans le corps du texte, il est possible cependant d'en dresser un inventaire complet: au fo 32, une esquisse du golfe de Smyrne (dessin présent $)^{12}$; au $\mathrm{f}^{\circ} 34$, le dessin de trois écussons observés par Galland au

${ }^{8}$ Frédéric Lyna, Catalogue des manuscrits de la Bibliothèque Royale de Belgique. Tome XI: Histoire de Hollande, mélanges d'histoire, géographie, voyages, itinéraires, expéditions, pp. 269-70.

${ }^{9}$ C'est la main de Langlès, comme nous le verrons plus loin.

${ }^{10}$ Galland: + Tome [raturé].

11 Smyrne: + avec une parabole [raturé] un traité des mours des Turcs comparées avec les nostres [1'ensemble est raturé].

${ }^{12}$ Le verso de ce folio est blanc; ce qui indique qu'il s'agit d'un feuillet indépendant ajouté par Galland, comme il le fit pour la plupart des autres dessins. La notice du catalo- 
château situé à l'entrée du port de Smyrne (dessin présent); au f ${ }^{\circ} 40$, le dessin d'une médaille et d'un médaillon frappés à Smyrne et représentant la déesse du Mont Sipyle tantôt couronnée de tours, tantôt assise dans un chariot tiré par deux lions (dessin arraché); au $\mathrm{f}^{\circ} 41^{\mathrm{v}}$, le dessin d'une médaille de bronze frappée à Smyrne qui représente Homère (dessin arraché); au fo 44 , le dessin d'une grosse tête de femme en marbre observée par Galland à l'entrée du château de Smyrne (dessin arraché); au f ${ }^{\circ} 109^{v}$, la figure d'une bêche particulière (dessin présent).

Ce texte a fait l'objet de multiples corrections et additions autographes, la plupart du temps interlinéaires ou marginales. Dans certains cas rares (deux pour être exact), les additions étant trop importantes pour figurer dans le texte même, elles ont été copiées sur des feuillets indépendants dont le format est, approximativement, équivalent à la moitié du type de feuillet qu'utilisa Galland pour le manuscrit. Ces feuillets, ajoutés après coup ${ }^{13}$, sont insérés respectivement comme suit ${ }^{14}$ : quatre feuillets (format: 175x110 mm.) foliotés (26 à 29), mais non paginés, placés entre les ff. 25 et 30 (ou pp. 46-47) ${ }^{15}$ et pris dans la reliure; enfin deux feuillets (format: 160x100 mm.) foliotés (69-70) et non paginés, pris dans la reliure entre les ff. 68 et 71 (ou pp. 122-123) ${ }^{16}$.

2) De la main de Galland également, le second texte porte le titre suivant qui, au contraire du texte précédent, n'a pas été raturé: Estat présent des Isles de Samos, Nicarie, Patmos et du Mont Athos par Joseph Georgerine, Archevesque de Samos. Traduit du grec vulgaire en françois par Antoine Galland, Antiquaire de sa Majesté Très Chré-

gue de la Bibliothèque Royale dit «dessin à la plume à peine ébauché du golfe de Smyrne» alors que le dessin est au crayon comme tous les dessins conservés dans le manuscrit.

${ }^{13}$ Ce que vient confirmer le fait qu'ils n'ont pas été paginés par Galland, comme il le fit cependant pour les autres folios.

${ }^{14}$ Un carré de papier, dont le verso est blanc, collé dans la marge extérieure du $\mathrm{f}^{\circ} 22^{\mathrm{v}}$ et qui n'est ni paginé ni folioté, porte l'écriture de Langlès qui y a recopié le texte d'une note marginale de Galland figurant au $\mathrm{f}^{\circ} 23$.

15 Cette addition commence par ces mots: Renvoi pour la page $47^{e}$ pour mettre a linea après ces mots qui fussent au dessus d'elle [c'est Galland qui souligne]. Au $\mathrm{f}^{\circ} 47$, à l'endroit désigné, figure une marque qui ressemble à un double zéro barré (๑)) que l'on retrouve au début du renvoi.

${ }^{16}$ Galland place au début de cet ajout les mots suivants: Renvoi pour la page 122 qu'il faut mettre a linea après ces mots: déclarée entre la France et l'Angleterre. On trouve au $\mathrm{f}^{\circ} 122^{\mathrm{v}}$, à l'endroit désigné, les mots: voiés le renvoi. 
tienne $^{17}$. Dans le coin inférieur gauche, on trouve cette date: MDCLXXIX, et son équivalent en chiffres arabes (1679) à l'opposé. Il couvre les ff. $138-183^{v}$, mais il avait été paginé préalablement par Galland de la façon qui suit: préface du traducteur (pp. 1-3/ff. 139-140), le texte traduit (pp. 1-83/ff. 141-183 ${ }^{\mathrm{v}}$ ).

3) Le troisième et dernier texte diffère des deux précédents en ceci qu'il ne s'agit pas d'un holographe de Galland, ni d'un de ces textes ou traductions, mais d'une lettre adressée à un destinataire anonyme. Elle court du f ${ }^{\circ} 185$ au f 196 et n'a pas été paginée par Galland. Elle est intitulée ( $\mathrm{f}^{\circ}$ 185): Relation de l'Isle de Tines ${ }^{18}$ contenue dans une lettre à Mons $^{r} * * * *$. L'auteur, un certain Jacques-Paul Babin ${ }^{19}$, jésuite de son état, signe à la fin ( $\mathrm{f}^{\circ} 196$ ) de Tines le 21 (raturé au profit de 3) avril 1679.

Le manuscrit dans son entier porte, au bas de chaque page, le paraphe $m d m$ correspondant au nom de Moreau de Mautour, que l'on trouve, par ailleurs, dans son entier à la fin des trois ouvrages, précédé de la mention leu et examiné, la mention leu, elle, étant répétée sur le premier folio des deux premiers textes.

\section{Histoire DU MS.}

Si l'histoire de ce manuscrit apparaît claire pour le $\mathrm{XX}^{\mathrm{e}}$ s., puisque nous en connaissons avec exactitude la date d'entrée (12 août 1912) à la Bibliothèque Royale Albert I ${ }^{\text {er }}$, nous devons bien reconnaître qu'elle est loin d'être aussi limpide pour les siècles précédents. Nous allons tâcher de la retracer pour chacun des textes en envisageant trois périodes, pour des questions de clarté: du vivant de Galland, à la mort de Galland, et la période intermédiaire qui sépare celle de la mort de Galland de l'entrée

${ }^{17}$ Ces six derniers mots ont été ajoutés par le censeur royal, Moreau de Mautour, sur lequel voyez infra.

${ }_{18}$ Il faut corriger la notice parue dans le catalogue de la Bibliothèque Royale, qui se base sur la table des matières décrites supra, celle-ci donnant la lecture Fines. Tines correspond à l'île de Tenos (en grec $\tau \eta v o s)$, parfois appelée Tino. C'est une petite île qui fait partie des Cyclades et se situe au S.-E. d'Andros et au N. de Délos.

${ }^{19}$ Et non Rabiri, comme on lira dans la notice du catalogue mentionnée supra qui, ici encore, s'en remet à la table des matières fautive qui ajoute, également, la lecture Rabier entre parenthèses. Nous renvoyons pour l'identification de cet auteur à la section $\mathrm{C}$, point $\mathrm{c}$. 
du manuscrit dans les collections de la Bibliothèque Royale Albert ${ }^{\mathrm{er}}$. Chacun des textes ayant sa propre histoire de même que le codex, puisqu'ils ont été rédigés à des dates différentes, nous étudierons chaque cas séparément pour ce qui est de la première période.

\section{Du vivant de Galland}

\section{a) Smyrne ancienne et moderne}

Comme nous l'avons rappelé dans l'introduction, Galland quitte une nouvelle fois la France vers le mois d'octobre 1677. Il est chargé par Jean Foy-Vaillant et l'abbé Giraud de partir à la recherche de médailles antiques qui devaient être offertes ou vendues au Cabinet des Médailles du Roi. Ces deux mécènes lui constituent un petit fonds destiné à couvrir ses dépenses ${ }^{20}$. De celui-ci, H. Omont devait déclarer ${ }^{21}$ : «On a point de détail sur ce voyage», tandis qu'Abdel-Halim qualifiait d'insignifiants les renseignements le concernant ${ }^{22}$ et précisait qu'il avait duré «un peu moins d'un an, dont un mois à Messine et le reste à Smyrne». Galland confirme lui-même cette durée dans sa préface à sa traduction de l'État présent ${ }^{23}:$ «j'entrepris un second voyage dans le Levant de dix à onze mois $^{24} \gg$. La redécouverte de sa relation nous permet de lever le voile opaque qui recouvrait cet épisode de sa vie.

Le texte débute par ces mots ( $\left.f^{\circ} 3\right)$ : «Messieurs, je vous ai écrit fort amplement le détail de mes avantures depuis mon départ de Toulon jus-

${ }^{20}$ M. Abdel-Halim, Antoine Galland, p. 59.

${ }^{21}$ Missions archéologiques françaises en Orient aux XVII et XVIII ${ }^{e}$ siècles. Vol. II, p. 203.

${ }_{22}$ M. Abdel-Halim, ibid.

${ }^{23}$ Voyez l'annexe 4 où figure la transcription complète de cette préface, d'après le texte se trouvant juste après celui de la Smyrne ancienne et moderne.

${ }^{24}$ L'information que donne Galland dans son autobiographie (Sommaire ou Mémoire chronologique de la vie d'Antoine Galland, conservé à la BnF, ms. fr. n. a., n ${ }^{\circ} 11403$, et édité par H. Omont dans son édition du Journal parisien d'Antoine Galland, 1708-1715, p. 10) selon laquelle son second voyage se fit dix-huit mois après être revenu du premier (donc vers la fin de l'été 1676!) doit être rejetée. Comme le fait remarquer à juste titre Abdel-Halim (ibid.), cette erreur est à mettre au compte du fait que Galland rédigea son autobiographie un peu plus de quatre décennies après cet événement: après un si long laps de temps, une erreur de date est compréhensible. L'information fournie dans la préface à la traduction de l'État présent est d'ailleurs corroborée par sa correspondance datée de Paris entre novembre 1676 et août 1677 (Abdel-Halim, ibid.). 
ques à mon arrivée à Messine, et pendant le séjour que j'y ai fait. Je continüe de vous faire part avec le mesme soin de mon arrivée à Smyrne, du séjour que j'y ai fait et de ce que j'y ai remarqué touchant ce qu'elle a estè autrefois et touchant l'estat auquel elle est aujourd'hui». Les quelques indices que ces lignes nous fournissent nous permettent d'établir avec certitude que son départ se fit de Toulon, probablement dans le courant du dernier trimestre de 1677. Ils soulèvent cependant un problème concernant la durée de son séjour à Messine. Abdel-Halim parle d'un mois $^{25}$, se basant sur l'autobiographie de Galland ${ }^{26}$. Or, Galland quitte Messine le 20 février $1678^{27}$. Le voyage de Toulon à Messine n'a pas pu s'étendre sur plus d'une semaine ou deux, à moins que le vaisseau n'ait fait plusieurs escales. Étant donné qu'il est clair qu'il quitta Toulon au début du mois d'octobre, ce voyage ayant duré de dix à onze mois, il devait donc déjà s'y trouver à la mi-octobre ou à la fin du même mois, la date exacte de son départ de Toulon nous étant inconnue. On peut donc considérer qu'il aurait séjourné entre trois à quatre mois à Messine, et non pas qu'un seul, comme on le pensait jusqu'à ce jour ${ }^{28}$, ou alors que le vaisseau vogua vers Messine entre le début d'octobre et la fin de janvier, marquant plusieurs escales; ce qui paraît impensable ${ }^{29}$. Désormais, nous savons également que Galland composa une relation de son séjour dans cette ville sicilienne qu'il envoya au même destinataire que sa Smyrne ancienne et moderne. Cette relation ne figure pas dans l'inventaire bibliographique de l'œuvre de Galland établi par Abdel-Halim ${ }^{30}$ et n'a pas été

25 M. Abdel-Halim, ibid.

${ }^{26}$ H. Omont, Journal parisien, ibid. Galland y déclare: «Dans ce voiage, pendant le séjour d'un mois qu'il fit à Messine, il se procura l'amitié d'Augustin Scilla [...]». C'est nous qui soulignons.

27 Smyrne ancienne et moderne, $\mathrm{f}^{\circ} 3^{\mathrm{v}}$.

${ }^{28}$ L'information que donne Galland dans son Voyage fait en Levant, Première lettre à l'abbé de la Chambre (Munich, Bayerische Staatsbibliothek, ms. gall. 727, p. 23), est explicite: "L'Autheur [Scylla], avec qui je fis amitié en passant par Messine il y a plus de dix-huit mois [...]», écrit-il à la fin du mois d'octobre 1679. Cette information vient bien corroborer le fait qu'il se trouvait à Messine au mois de février 1678.

${ }^{29}$ On vient de voir (note 24) que Galland avait déjà commis une erreur d'estimation, dans son autobiographie, concernant la durée totale de ce second voyage. Il n'est donc pas impossible que la durée de son séjour à Messine soit, elle aussi, erronée.

${ }^{30}$ M. Abdel-Halim, Antoine Galland, pp. 476-88.

Galland déclare pourtant en 1701: «Je ne vous parlois pas des relations de mes voyages, de Messine, de Malte, des isles de l'Archipel, d'Andrinople, des environs de Cons- 
retrouvée depuis lors. De ce séjour, nous ignorons donc tout, à l'exception du fait qu'il y lia connaissance avec un savant italien du cru, Agostino Scilla (1629-1700), qui était tout à la fois peintre, antiquaire, médecin et philosophe. Celui-ci lui offrit un exemplaire de son traité sur les pétrifications de corps marins ${ }^{31}$ que Galland traduira en français ${ }^{32}$.

Galland quitte donc Messine le 20 février 1678. La dernière date qu'il mentionne est le 8 mars, moment de son arrivée à Smyrne. La date de son départ de Smyrne n'est pas indiquée dans sa relation, mais elle peut être conjecturée d'après une lettre que son ami Jacob Spon (1647$1685)^{33}$ adresse à Nicaise le 9 septembre 1678 et où il déclare ${ }^{34}$ : « $M$.

tantinople, des côtes d'Asie, etc. etc.». Lettre adressée à P.-D. Huet, de Caen le 25 février 1701, et éditée par M. Abdel-Halim, Correspondance, pp. 362-3.

31 Agostino Scilla, La vana speculazione disingannata dal senso, lettera risponsiva circa $i$ corpi marini che petrificati si trovano in varij luoghi terrestri [...]. In Napoli, appresso Andrea Colicchia, 1670, in- $4^{\circ}$, [4ff]-168 p., XXVIII pl. et front. Par pétrifications, il faut entendre fossiles.

32 Galland enverra sa traduction à son ami Jacob Spon de Lyon, qui se propose de la faire publier. $V$. à ce sujet Abdel-Halim, Antoine Galland, p. 303 (note 13) et Galland, Voyage fait en Levant (1679-1680), Première lettre à l'abbé de La Chambre, ibid. On connaît la raison pour laquelle le texte ne parut finalement pas. Galland ajouta dans la marge de son Voyage fait en Levant (ibid.), lors d'une relecture, que Spon n'avait pas pu obtenir les planches de l'édition originale. Pour éviter les coûts qu'entraînait la gravure des planches, les éditeurs préféraient acheter ou emprunter les planches qui avaient servi pour l'édition originale. Spon n'ayant pu se les procurer, le projet tomba à l'eau. Cette note marginale est mal reproduite par M. Abdel-Halim, ibid., qui s'était basé sur l'édition préparée par $\mathrm{Cl}$. Brigault dans le cadre d'un mémoire de fin d'études. Ce dernier s'est contenté, semble-t-il, de retranscrire le texte qui fut remanié par un relecteur postérieur à Galland, Langlès en l'occurrence, texte qui fut écrit sur un morceau de papier rapporté sur la note marginale. Nous transcrivons ici la note de Galland: «Mr Spon, qui mou<rut $>$ en 1686 [sic] n'a pas <fait $>$ imprimer cett $<e>$ traduction par $<c e>$ qu'il n'avoit $p<u>$ avoir les planch $<$ es $>$, sans quoi il n'<estoit $>$ pas possible [...] traduction par [...] et ie ne scai ce <qu'elle> sera devenüe d<ans> le temps <qu'il dut> s'enfuir de Lyon». Ces derniers mots, après «le temps», ont été raturés par Galland qui a écrit au-dessous l'ajout suivant: «qu'il fut contra $<$ int $>$ de s'enfuir de Lion $<$ estant $>$ suiet de la Religion $<P r>d u$ temps de la révocation de l'Edit de <Nantes $>$ ».

La révocation de l'Édit de Nantes (1685) viendra donc aussi contrecarrer ce projet, Spon, protestant, devant quitter Lyon et se réfugier en Suisse, où il mourra en décembre 1685. A partir de ce moment, Galland ne parviendra jamais à récupérer son texte.

${ }^{33}$ Sur Spon, $v$. plus récemment Jacob Spon: un humaniste lyonnais du XVII siècle. Catalogue d'une exposition qui s'est tenue à Lyon du 20 octobre au 8 décembre 1993, dont les textes ont été réunis sous la direction de Roland Étienne et Jean-Claude Mossière. Lyon: Bibliothèque Salomon-Reinach, 1993, 326 p.

${ }^{34}$ Lettre conservée à la $\mathrm{BnF}$, fonds fr., $\mathrm{n}^{\circ}$ 9360, fo 214 . Citée par Abdel-Halim, Antoine Galland, p. 60 (note 60). 
Galland qui est revenu depuis peu du Levant [...]». On peut donc supposer qu'il était de retour à Paris vers la fin du mois d'août et qu'il avait quitté Smyrne au début du même mois.

Pour l'aider dans la rédaction de ses relations de voyage, Galland avait pris la bonne résolution, assez tôt semble-t-il ${ }^{35}$, de consigner dans un journal les événements des journées écoulées. Cette habitude, il la maintiendra jusqu'au bout puisque ses dernières notes remontent à deux semaines avant sa mort ${ }^{36}$. La relation du voyage à Smyrne fut commencée à Smyrne même, comme l'indiquent certains indices.

Il apparaît clairement que le texte, qui fut envoyé à un destinataire (ou plusieurs), sur l'identité duquel nous reviendrons plus loin, fut recopié par Galland à partir d'un original aujourd'hui disparu. Parmi les éléments qui viennent confirmer cette affirmation figurent les inévitables erreurs inhérentes à la copie d'un ouvrage: répétitions, haplologies,...

${ }^{35}$ La plus ancienne référence faite par Galland à son Journal date de 1669: il avait alors 23 ans. V. M. Abdel-Halim, Antoine Galland, p. 415.

${ }^{36}$ De ce journal, il ne subsiste plus de nos jours que deux fragments. Le premier contient deux années (1672-73) passées à Constantinople, lors de sa première expérience orientale. Les manuscrits autographes en sont conservés à la $\mathrm{BnF}$, fonds fr., $\mathrm{n}^{\text {os }} 6088$ 6089. Ce journal fut édité pour la première fois par Charles Schéfer en 1881 (Paris, E. Leroux, 2 vol.) s. 1. t. Journal d'Antoine Galland pendant son séjour à Constantinople (1672-1673), accompagné d'une préface et de notes. Cette édition a récemment fait l'objet d'une réimpression anastatique (Frankfurt am Main, Institute for the History of Arabic-Islamic Science, 1994). L'édition originale fut traduite en turc par Nahid Sirri Orik (Ankara, Türk tarih kurumu Başımevi, 1949) s. 1. t. Antoine Galland İstambul'a ait günlük hâtiralar. Le second fragment contient le journal des années passées à Paris (1708-1715). Les manuscrits autographes sont conservés à la BnF, fonds fr., $\mathrm{n}^{\text {os }} 15277$ 15280. Certaines parties furent publiées par Taschereau et Reinaud dans la Revue rétrospective, deuxième série (1837), t. XII, pp. 1-69 et 226-291. Des extraits des années 17101711, probablement sélectionnés par A. Millin, sont parus dans la Nouvelle revue encyclopédique III, pp. 307-320 et 477-488 (Paris, 1877). Ces deux éditions sont qualifiées de maladroites par M. Abdel-Halim, Antoine Galland, p. 416. Une nouvelle édition basée sur des extraits fut ensuite accomplie par H. Omont s. 1. t. Journal parisien d'Antoine Galland, 1708-1715 [dans Mémoires de la Société de l'histoire de Paris et de l'île de France, t. XLVI], Paris, 1919. Ce journal a récemment fait l'objet d'une analyse littéraire et historique. V. J. Miquel-Ravenel, À la rencontre d'Antoine Galland, premier traducteur des Mille et une nuits, dans Arabica 41 (1994), pp. 147-61. L'auteur de ces lignes a entrepris l'édition de ce journal couvrant les annés 1708 à 1715.

À titre de comparaison, Jean Chardin, un contemporain qui passa à la postérité pour la relation de ses voyages en Perse, tandis que Galland n'est connu que pour sa traduction des Mille et une nuits, consignait également ses remarques et impressions dans des «mémoires» sur lesquels il se basa plus tard pour rédiger sa relation qu'il appelait «journal». V. D. Van der Cruysse, Chardin le Persan, p. 215.

Journal Asiatique 289.1 (2001): 1-66 
Citons, à titre d'exemples, un doublet raturé au fo 52 («il a encor l'avantage»), ou encore ce problème de justification au $\mathrm{f}^{\circ} 68^{\mathrm{v}}$ : au bout de la ligne, il commence à écrire le mot «grande», mais il ne dispose de place que pour les trois premières lettres du mot. Il les rature et l'écrit à nouveau à la ligne suivante ${ }^{37}$. Dans certains cas, nous sommes poussé à croire que Galland réalisa cette copie sous la dictée. Comment expliquer autrement certaines erreurs telles que celles-ci: $\mathrm{f}^{\circ} 12^{\mathrm{v}}$ (a quase), $\mathrm{f}^{\circ}$ 18 (qui y appo abordent) ${ }^{38}$ ?

Tout bon voyageur qui se respecte, qu'il soit de ce siècle ou de l'époque de Galland, emporte avec lui des guides qui l'aideront sur place. Au $\mathrm{XVII}^{\mathrm{e}}$ siècle, le lettré qui se rend en Orient emporte surtout les récits de voyages des prédécesseurs, mais aussi les références de la littérature classique, car l'un de leurs soucis majeurs est de pouvoir identifier les sites anciens ${ }^{39}$. Galland ne fait pas exception à la règle. Sa relation comprenant une histoire ancienne de la ville de Smyrne, il lui fallait disposer sur place d'ouvrages en latin et en grec traitant de la ville. Dans le cas qui nous occupe, il eut à sa disposition, entre autres, les textes de Strabon, Pausanias et Stéphanus (Étienne de Byzance), «qui sont, comme vous scavès, les seuls autheurs dont je me suis muni en partant de Paris remettant a suppléer ce que les autres autheurs en ont dit lorsque je serai de retour et que je pourrrai jouir de mes livres» ( $\mathrm{f}^{\circ} 23$ ). Ces mots sont raturés et Galland les a remplacés dans la marge par ceux-ci: «Aristide et quelques autres autheurs qui en ont parlé très avantageusement». Cette correction nous indique qu'il a bien retravaillé le texte dès son re-

37 Voici d'autres exemples de sauts du même au même et de lapsus calami: fo 8 (les estes autres estoient destinées pour les costes de Syrie), $\mathrm{f}^{\circ} 20^{\mathrm{v}}$ (le Golfe de Midy Smyrne sur le Midy), $f^{\circ} 35^{v}$ (un hippodrome), $f^{\circ} 36^{v}$ (et non par les coins (doublet)), $f^{\circ} 47$ (avec grand une grande), $\mathrm{f}^{\circ} 47^{\mathrm{v}}$ (sur un c'est a dire sur une), $\mathrm{f}^{\circ} 51^{\mathrm{v}}$ (leur etrré p imam ou curé pour), $\mathrm{f}^{\circ} 72^{\mathrm{v}}$ (en Furq Chrétienté), $\mathrm{f}^{\circ} 73^{\mathrm{v}}$ (que quoiqu' soit qu'ils voyagent), $\mathrm{f}^{\circ} 74^{\mathrm{v}}$ (à Cons la Porte), fo 84 (tes Anglois les François, les Anglois), fo 98 (est sur ceux (doublet)), $f^{\circ} 104$ (le Gr Sa Hautesse le Gr Visir), f 110 (aux environs par les mais [...] par les cheveux), ibid. (jusqu'atto depuis la mer jusqu'aux), $\mathrm{f}^{\circ} 111^{\mathrm{v}}$ (que l'on ap a son honneur que l'on appeloit), $\mathrm{f}^{\circ} 114^{\mathrm{v}}$ (j'avance at brttit [...] au bruit), $\mathrm{f}^{\circ} 121^{\mathrm{v}}$ (les etillters Turcs mangent les premières avec des cuillers), fo 126 (se plaisent soient fort courts, et se plaisent).

38 On retrouve aussi ce phénomène dans le Voyage fait en Levant. Par exemple, dans le tome I (Munich, cod. gall. 727): p. 174 (ful funèbre), p. 179 (d'un anehe ge).

${ }^{39}$ Chardin vit partir en fumée tous les ouvrages qu'il avait emportés au cours de l'attaque d'une bande armée. V. D. Van der Cruysse, op. cit., p. 155. 
tour à Paris, à partir du mois d'août $1678^{40}$. On sait du reste qu'il entreprit à cette époque de rédiger et de mettre au net plusieurs projets d'écriture: des relations de voyage, parmi lesquelles la Smyrne ancienne et moderne, mais aussi quatre traductions ${ }^{41}$. Une partie du travail fut d'ailleurs accomplie durant le long séjour qu'il fit à Marseille dès janvier 1679, dans l'attente de la nomination du nouvel ambassadeur auprès de la Porte, avec lequel il devait finalement s'embarquer à Toulon en septembre de la même année.

Toutefois, Galland termina la relecture ainsi que les corrections et les additions $^{42}$ de la Smyrne ancienne et moderne avant son départ pour Marseille (avant janvier 1679 et entre septembre et décembre 1678

40 M. Couvreur et D. Viviers ont soutenu dans deux articles (Jacob Spon, à travers un manuscrit inédit de la Bibliothèque Royale de Belgique, dans Jacob Spon: un humaniste lyonnais au XVII siècle, pp. 247-56; Galland se relit: correction ou censure?, dans Revue belge de philologie et d'histoire 72 (1994), pp. 585-93) que le manuscrit bruxellois contient des corrections autographes de Spon (entre autres ff. $3^{\mathrm{v}}-4,4^{\mathrm{v}}, 15^{\mathrm{v}}, 22,23,24,25$ $25^{\mathrm{v}}, 30^{\mathrm{v}}, 33$ ) et que la troisième pièce figurant dans le manuscrit (Relation de l'Isle de Tines du père Babin) était totalement de sa main (v. Jacob Spon, p. 249). Sans trop entrer dans le détail, nous souhaiterions réfuter ici la première affirmation que nous jugeons sans fondement. Soulignons, avant tout, que les auteurs se contredisent d'un article à l'autre: des corrections attribuées à Spon dans le premier article (p. 253) sont devenues celles de Galland dans le second (p. 588). D'autre part, une simple comparaison paléographique des notes qui seraient de la main de Spon dans la Smyrne ancienne et moderne et de l'écriture de la Relation de l'Isle de Tines du père Babin qui, rappelons-le, est une copie de Spon, révèle qu'il s'agit de deux mains complètement différentes $(v$. annexe 6 à la fin de cet article, $\mathrm{n}^{\mathrm{os}} 1$ et 2). Mais de qui sont alors les corrections interlinéaires et marginales dans la Smyrne ancienne et moderne que Couvreur et Viviers attribuent à Spon? Elles sont bien entendu de Galland ( $v$. à l'annexe 6 , les $n^{\text {os }} 1$ et 3 ). L'écriture diffère quelque peu, mais il ne faut pas perdre de vue que Galland s'était appliqué à recopier son texte, avec minutie comme cela se remarque, et que les notes et corrections sont postérieures, dans certains cas de plusieurs années, à la copie: l'âge, l'encre, la plume, les circonstances modifient quelque peu l'écriture d'un homme. L'écriture de ces additions et de ces corrections est par ailleurs identique à celle que l'on trouve pour le travail de révision de Galland dans son Voyage fait en Levant (Munich, cod. gall. 727 et 728, v. annexe 6, $\mathrm{n}^{\text {os }} 4$ et 5).

${ }^{41}$ Le traité des pétrifications d'Agostino Scilla, rencontré lors de son séjour à Smyrne, des proverbes grecs, l'État présent des îles de Samos, Nicarie, Patmos et du Mont Athos de Joseph Georgirènes, et un manuscrit turc racontant la révolte des janissaires qui aboutit au rétablissement de Mustafa sur le trône. V. M. Abdel-Halim, Antoine Galland, p. 61.

${ }^{42}$ Parmi celles-ci, nous citerons bien sûr l'ajout concernant Aristide signalé supra, mais aussi les additions qui figurent sur les feuillets intercalaires, de format plus petit, que nous avons mentionnés au moment de la description du manuscrit. Ces additions sont, pour la plupart, également tirées d'Aristide.

Journal Asiatique 289.1 (2001): 1-66 
donc), comme le laisse supposer une information contenue dans une lettre adressée par l'éditeur parisien Barbin à Spon et qui est datée du 20 juin $1679^{43}$. Barbin y déclare: «pour la relation de Samos Patmos \& c de M. Gallant, j'en pourois traiter si je voyais ce que c'est, non pas dans le dessein d'augmenter l'archipel que j'ay imprimé car je ne l'estime pas assez pour lui donner des Ilustrations, mais je le pourois joindre avec sa Smirne ancienne et nouvelle qu'il m'a laissé ${ }^{44} \gg$. Nous savons donc que Galland avait eu la ferme intention de faire publier cette relation. Il avait déjà eu affaire à Barbin ${ }^{45}$, qui lui avait été présenté par Jacob $\mathrm{Spon}^{46}$, une année auparavant. L'imprimeur avait en effet publié son premier ouvrage: une traduction d'un manuscrit turc, relatant la révolte des janissaires qui avait conduit à la mort du sultan 'Uțān, qui parut en 1678, tandis que Galland se trouvait encore à Messine, sous le titre de La Mort du Sultan Osman, ou le rétablissement de Mustafa sur le Thrône ${ }^{47}$. Cette première expérience avait manqué se révéler désastreuse, Barbin ayant soumis l'ouvrage à la relecture d'un obscur abbé qui était chargé d'y insérer des aventures amoureuses, afin de le rendre plus attrayant pour un

${ }^{43}$ Bibliothèque municipale de Lyon, ms. 1721, lettre 129. Je remercie vivement M. Pierre Guinard, conservateur en chef de la Bibliothèque municipale de Lyon, pour m'avoir fait parvenir gracieusement une copie de cette lettre et d'autres citées infra. On en trouvera une transcription complète sous l'annexe 1.

${ }^{44}$ C'est nous qui soulignons.

45 Barbin était un des principaux libraires de Paris. Il eut l'heur de publier quelquesuns des chefs-d'œuvre de la littérature française du XVII ${ }^{\mathrm{e}} \mathrm{s}$. tels que les ouvrages de Molière, de La Rochefoucauld, les Lettres portugaises de Guilleragues, les Fables de La Fontaine, mais aussi les Voyages de Tavernier, Le Courronement de Soleymaan III, roi de Perse de Chardin, la Bibliothèque orientale de Barthélemy d'Herbelot de Molainville à laquelle, soit dit en passant, Galland prit part, etc. Molière allait d'ailleurs l'immortaliser en le citant dans une de ses pièces: Les Femmes savantes («Hé bien! nous nous verrons seul à seul chez Barbin». Cité par G. Reed [v. les références infra]). En dépit de ces importantes publications, Barbin reste une énigme, encore de nos jours. Les quelques pièces historiques le concernant ont été étudiées par Gervais E. Reed qui s'est basé sur celles-ci, ainsi que sur d'autres éléments utiles, pour en dresser une biographie et étudier son travail d'imprimeur. Cette étude est parue sous le titre suivant: Claude Barbin, libraire de Paris sous le règne de Louis XIV, Genève-Paris (Librairie Droz), Centre de recherches d'histoire et de philologie de la IVe Section de l'École pratique des Hautes Études (VI: Histoire et civilisation du livre, 5), 1974, XI-131 p.

${ }_{46}$ M. Abdel-Halim, Antoine Galland, p. 57.

${ }^{47}$ L'ouvrage n'apparaît pas dans la liste des publications de Barbin dressée par G. E. Reed, à la fin de son ouvrage (pp. 86-118). Galland n'y figure que pour les sept premiers tomes des Mille et une nuits ( $\mathrm{n}^{\text {os }} 608,613$ et 618 ). 
public friant ${ }^{48}$. On suppose que ce fut Jean Foy-Vaillant qui parvint à faire changer d'avis Barbin. Toujours est-il que les passages en question n'y furent pas intégrés et que l'ouvrage garda toute son intégritét ${ }^{4}$. Pour en revenir à la Smyrne ancienne et moderne, la lettre de Barbin nous indique qu'en date du mois de juin 1679, il avait l'intention de la publier avec l'État présent des îles de Samos, Nicarie, Patmos et du Mont Athos. Nous ignorons totalement quels sont les faits qui ont empêché son impression $^{50}$. En avril 1680, alors qu'il se trouve de nouveau à Smyrne, Galland pense que l'affaire va bon train puisqu'il déclare à Spon, le destinataire de la lettre ${ }^{51}$ : «Obligés moi de m'envoier un exemplaire de

${ }^{48}$ Cet événement est rapporté par Charpentier dans une lettre qu'il avait adressée à Spon le 2 mars 1678. Cette lettre est conservée à la Bibliothèque municipale de Lyon, ms. 1720 , lettre 64 . Une transcription complète en est donnée sous l'annexe 2.

${ }^{49}$ Galland n'était pas au bout de ces peines avec la maison Barbin. Il dut à nouveau expérimenter la fourberie de cette maison, dont l'éditeur était décédé entre-temps (en 1698) et qui fut dorénavant dirigée par sa veuve dans un premier temps, puis par la veuve Ricœur, au moment de la publication du huitième volume des Mille et une nuits en 1709. Celui-ci étant jugé trop maigre par l'imprimeur, ce dernier prit la décision d'y ajouter deux contes tirés des Mille et un jours de Pétis de la Croix. Furieux, Galland mit fin à sa collaboration avec la maison Barbin, qui put malgré tout se consoler avec la publication des cinq volumes des Mille et un jours de Pétis de la Croix. V. à ce sujet M. Abdel-Halim, Antoine Galland, p. 269 et suiv., et G. May, Les Mille et une nuits d'Antoine Galland, pp. 84-5.

${ }^{50}$ En l'absence de documents probants, nous ne pouvons que conjecturer une fois de plus sur la raison de ce dédit. On sait que Barbin eut un contact suivi avec Guillet de Saint-George entre 1671-1681. Il publia encore en 1681 l'Histoire du règne de Mahomet II de ce dernier, ouvrage pour lequel il obtint un privilège le 2 janvier 1681. V. Enregistrements des privilèges commençant au $23^{e}$ octobre $1673, \mathrm{BnF}$, ms. fonds fr., $\mathrm{n}^{\circ} 21946$, p. 121 ( $\mathrm{n}^{\circ}$ 917). Une polémique étant née entre Spon et Guillet ( $v$. à ce sujet infra le point E), Barbin ne souhaitait pas voir ses ventes diminuer à cause de celle-ci. Ses relations avec Guillet, s'il avait publié les textes de Spon et de Galland, s'en seraient ressenties. Or Spon avait préparé une Réponse à la Critique publiée par M. Guillet sur le Voyage de Grèce de Jacob Spon, ouvrage pour lequel il obtint le privilège de la communauté des Maîtres libraires-imprimeurs de Paris le 8 juin 1679 (v. G. E. Reed, op. cit., p. 65). L'ouvrage parut à Lyon la même année. L'échange épistolaire entre Spon et Barbin concernant la Smyrne ancienne et moderne ainsi que les deux autres textes datent du 20 juin et du 20 juillet. Ce fut peut-être à cause de la publication de la Réponse de Spon que Barbin subit des pressions de la part de Guillet ou de quelque de ces amis influents? On verra, d'autre part, les scrupules de Barbin s'agissant de l'Histoire et l'Estat de la ville de Genève que Spon lui avait proposée pour publication ( $v$. annexe 1), et pour laquelle Spon demanda, finalement, un privilège royal, un peu plus tard, le 12 août 1679. V. Enregistrements des privilèges commençant au $23^{e}$ octobre $1673, \mathrm{BnF}, \mathrm{ms}$. fonds fr., $\mathrm{n}^{\circ} 21946, \mathrm{p} .89$ $\left(\mathrm{n}^{\mathrm{o}}\right.$ 691).

${ }^{51}$ Lettre à Spon datée du 3 avril 1680 et écrite de Smyrne. $V$. M. Abdel-Halim, Correspondance, pp. 142-3 et la citation par le même dans Antoine Galland, p. 302.

Journal Asiatique 289.1 (2001): 1-66 
Smyrne ancienne et moderne quand l'impression en sera achevée». À tel point qu'il pense pouvoir y faire des corrections et la compléter en cas de nouvelle édition: «Mais au cas que Smyrne ancienne et moderne ait du débit, et que Barbin en veuille faire une seconde édition, je vous prie de le faire différer jusqu'à ce que j'aye pû envoier de quoi la corriger et l'augmenter ${ }^{52}$ ».

Galland dut être fort désappointé d'apprendre que l'ouvrage ne parut finalement pas. La durée de son troisième voyage en Orient, le plus long de sa carrière ( 9 ans et trois mois), et la distance qui le séparait de la métropole n'ont pas dû faciliter les choses et ce, en dépit des multiples amis sur lesquels il pouvait déjà compter à cette époque. Mais nous pouvons supposer qu'il ne souhaita pas en rester là: Galland retravailla plusieurs de ses textes jusqu'à la fin de sa vie ${ }^{53}$, et il semble que ce fut aussi le cas pour cette relation, en dépit du fait qu'il ne la mentionne plus explicitement dans son Journal ou sa Correspondance, écrits durant les dernières années de sa vie ${ }^{54}$.

\section{b) Estat present des Isles de Samos, Nicarie, Patmos et du Mont Athos}

Dans l'intervalle qui sépare son retour de son premier voyage au Levant (1675) et le départ pour le second (1677), Galland rencontra à Paris un ancien archevêque de Samos, du nom de Joseph Georgirènes ${ }^{55}$, avec lequel il avait lié connaissance quelques années auparavant, puisqu'il semble bien que ce dernier fut son professeur de grec moderne au cours de son séjour à l'ambassade de France à Constantinople ${ }^{56}$. L'archevêque

52 Ibid.

53 Ce fut le cas notamment de ses Remarques sur l'Estat présent de l'Empire ottoman traduit de l'anglois de M. Ricaut et les notes adjoustées par M. Bespier, composées en 1682 et qu'il revit encore en 1714, quelques mois avant de trépasser. $V$. M. Abdel-Halim, Antoine Galland, p. 302-3.

54 Certaines relations de voyages, sans préciser lesquelles, furent révisées peu avant 1701 (lettre du 25 février 1701 à Huet) et il comptait qu'il aurait encore besoin de beaucoup de loisir pour faire de même avec le reste. V. M. Abdel-Halim, Antoine Galland, p. 319, note 88. Ces propos exacts sont «Il y en a une partie au net; mais j'aurai besoin de loisir que je n'ai pas pour y mettre le reste». V. Id., Correspondance, p. 363. Enfin, il est certain que Galland apporta des additions à son Voyage fait en Levant après 1688, et de nouveau après 1691. V. M. Couvreur et D. Viviers, Galland se relit: correction ou censure?, dans Revue belge de Philologie et d'Histoire 72 (1994), p. 591.

55 Galland orthographie son nom comme suit: Georgerine.

56 V. Abdel-Halim, Antoine Galland, p. 35 
résidant plusieurs mois dans la capitale française, Galland profita de l'occasion pour lui demander de rédiger une description de l'Archipel grec, plus particulièrement des îles de Samos, de Nicarie, de Patmos et du Mont Athos. Galland avait en effet conçu le projet d'écrire une description générale de l'Archipel qui soit la plus fidèle possible. Cette source de première main représentait donc à ses yeux une mine d'informations qu'il souhaitait mettre à profit. Georgirènes céda à sa demande et se mit à l'œuvre rapidement, Galland s'étant engagé à traduire les pages écrites au fur et à mesure que l'auteur les lui communiquerait. Sa tâche terminée, Galland apprit que l'auteur allait se rendre à Londres, emportant dans ses paquets la précieuse traduction tout en lui laissant l'original grec. Notre traducteur s'engagea alors vis-à-vis de l'auteur à ne pas faire imprimer une seconde version, qu'il souhaitait mettre en chantier, tant qu'une version anglaise n'aurait pas paru. Déconfit, il fit contre mauvaise fortune bon cœur et donna sa parole. Sans nouvelle de Georgirènes, il accomplit entre-temps son second voyage, qui le conduisit à Smyrne (1677-1678). Dès son retour, à la fin du mois d'août, il se consacra à la mise au net de plusieurs de ses écrits, et ce ne fut qu'arrivé à Marseille, à la fin de 1678, dans l'attente de s'embarquer pour la troisième fois à destination de l'Orient, qu'il apprit la parution de la version anglaise du texte de Georgirènes. Galland se sentit alors libéré de sa promesse et entreprit une nouvelle traduction du texte à partir de la version anglaise, puisqu'il apparaît que le manuscrit original en grec moderne était soit resté à Paris, soit n'était plus en sa possession, mais dont il pouvait toutefois se remémorer une grande partie ${ }^{57}$.

Si l'histoire de ce texte peut être retracée aussi précisément, c'est qu'à la différence de la Smyrne ancienne et moderne, il est conservé en plusieurs exemplaires. Hormis la copie autographe de Bruxelles, inédite jusqu'il y a peu, Abdel-Halim en avait dénombré deux: une copie incomplète, puisqu'elle ne contient pas la préface du traducteur, conservée à la Bayerische Staatsbibliothek de Munich sous la cote cod. gall. 751, et une autre, complète celle-là, mais probablement non autographe, qui fut

57 Tous ces renseignements sont fournis par Galland lui-même dans la préface qu'il écrivit pour la seconde version. On trouvera une transcription complète de cette préface d'après le texte figurant dans le codex bruxellois à l'annexe 4. V. aussi Abdel-Halim, ibid., pp. 305-7.

Journal Asiatique 289.1 (2001): 1-66 
conservée à la Bibliothèque de l'École des Langues Orientales dénommée, depuis lors, Institut National des Langues et Civilisations Orientales (INALCO) ${ }^{58}$. Abdel-Halim mentionne, de plus, une troisième copie qui apparait dans le catalogue de la bibliothèque du célèbre orientaliste français, Louis-Mathieu Langlès, dispersée à sa mort ${ }^{59}$. Pour notre part, nous sommes d'avis que le manuscrit Langlès et celui conservé à $\mathrm{Mu}$ nich ne font qu'un. Tout comme les deux tomes de la relation de voyage des années 1679-1680 (Voyage fait en Levant, cod. gall. 727-728), il passa, à la mort de Langlès, dans les mains de l'orientaliste français Étienne Quatremère, dont la collection de livres fut acquise par la bibliothèque de Munich $^{60}$. Par ailleurs, il semble correspondre à la première version de la traduction préparée par Galland alors qu'il était encore à Paris, travaillant au fur et à mesure que l'auteur lui fournissait les cahiers à traduire; ce qui explique l'absence de préface, qui figure pourtant dans le manuscrit autographe de Bruxelles, de même que dans la copie de l'INALCO portée disparue. Pour rappel, l'auteur avait emporté la première version de la traduction de Galland à Londres, lui laissant l'original grec. Galland ne devait pas la revoir, et c'est pourquoi il en entreprit une seconde, dont l'original est conservé dans le manuscrit bruxellois. On ignore comment Langlès put se procurer le manuscrit de la première

${ }^{58}$ Cet exemplaire fut encore consulté par É. Legrand, qui transcrivit complètement la préface de Galland dans son ouvrage intitulé Bibliographie hellénique ou description raisonnée des ouvrages publiés par des Grecs au dix-septième siècle, tome II, pp. 342-8 $\left(\mathrm{n}^{\circ} 539\right.$, où il est décrit de la façon suivante: in- $4^{\circ}, 3 \mathrm{ff}$. non chiffrés, $66 \mathrm{pp}$.). AbdelHalim n'a pu retrouver le manuscrit à la bibliothèque en question (Antoine Galland, p. 307, note 34). Il semble donc avoir disparu entre 1894 (date de la publication de l'ouvrage de Legrand) et 1964 (date de parution de la thèse d'Abdel-Halim).

59 Abdel-Halim, Antoine Galland, p. 307, note 32, et Catalogue des livres, imprimés et manuscrits, composant la bibliothèque de feu M. Louis-Mathieu Langlès, pp. 531-2 $\left(\mathrm{n}^{\circ} 4352\right.$ décrit comme «manuscrit autographe, petit in- $8^{\circ}$, relié en carton»).

Il en existe encore un quatrième exemplaire qui est mentionné par H. Omont, Missions archéologiques., vol. II, p. 1203 (note 1): Berlin, ms. Hamilton 247. Cette note semble avoir échappé à Abdel-Halim.

60 Abdel-Halim n'avait pas fait ce lien ou, du moins, il n'en parle pas explicitement. Cette hypothèse est pourtant étayée par la notice ajoutée par un conservateur de la bibliothèque bavaroise dans le manuscrit de l'État présent: «Der Übersetzer ist der französiche Orientalist Antoine Galland (1646-1715). Nach seinem Tod war die Handschriften zusammen mit Cod. gall. 727 u. 728 im Besitz des französichen Orientalisten Louis-Mathieu Langlès, der die 3 Handschriften d. h. Cod. gall. 727, 728, 751 publizieren wollte» $\left(\mathrm{f}^{\circ} \mathrm{II}^{\mathrm{v}}\right.$ ). Pour plus de détails, $v$. le point 3 infra. 
version, mais celui-ci ne faisait pas partie des manuscrits légués par Galland à la bibliothèque du Roi. Nous en voulons pour preuve l'absence du sigle «mdm» placé au bas de chaque page par Moreau de Mautour, censeur royal, qui fut chargé de relire les manuscrits de Galland susceptibles d'être publiés à titre posthume. Ce paraphe apparaît bien dans l'ensemble du manuscrit bruxellois, mais aussi dans les deux volumes du Voyage fait en Levant (1679-1680) ainsi que dans d'autres textes, comme nous le verrons plus en détail dans la suite de cet article.

Comme nous l'avons souligné au point précédent, l'État présent devait être publié par Barbin en même temps que la Smyrne ancienne et moderne. Mais à la différence de cette dernière, que Galland avait laissée à l'imprimeur avant son départ de Paris, la nouvelle traduction de l'État présent fut entreprise pendant son séjour à Marseille. Cependant, elle était achevée avant le 20 juin 1679, puisque c'est la date de la réponse de Barbin à Spon dans laquelle le premier marque son désir de la voir et de la faire lire ensuite par Jean Foy-Vaillant ${ }^{61}$. Galland a d'ailleurs inscrit la date de 1679, en chiffres romains, sur la page de titre. Dès lors qu'il se trouvait de nouveau en Orient, quelques semaines plus tard, il devait ignorer l'intention de Barbin de joindre ce texte à sa Smyrne ancienne et moderne. Du moins dans un premier temps, puisqu'il ne parle pas de l'État présent dans sa lettre à Spon du 3 avril 1680 et envoyée de Smyrne. On n'en trouve pas plus de trace dans sa Correspondance après cette date. Il apparaît que, tout comme pour Smyrne ancienne et moderne, il ne perdit pas espoir de faire paraître cette traduction comme en témoignent les notes qu'il apporta par la suite au manuscrit de Bruxelles ${ }^{62}$.

\section{c) Relation de l'isle de Tines}

Quant au troisième texte préservé tout à la fin du manuscrit bruxellois, il diffère des deux précédents en ceci qu'il n'est pas de la main de Galland, mais de Spon. Il consiste en une lettre, intitulée par son auteur Relation de l'Isle de Tines, contenue dans une lettre à Mons ${ }^{r}$. ****, qui fut composée et expédiée de l'île du même nom le 21 avril 1679, cette date ayant été raturée, par la suite, au profit du 3 du même mois. Nous en

${ }^{61} \mathrm{~V}$. l'annexe 1.

${ }^{62}$ Ff. 148, 165v $, 170,171$. 
connaissons l'auteur qui se nomme à la fin: il s'agit de Jacques-Paul Babin $^{63}$, révérend père jésuite ${ }^{64}$. Celui-ci n'était pas inconnu du milieu des voyageurs puisqu'il avait eu l'heur de donner une Relation de l'état présent de la ville d'Athènes, ancienne capitale de la Grèce, qui passe pour la plus exacte description qui ait été donnée de cette ville au $\mathrm{XVII}^{\mathrm{e}}$ s. Il adressa cette relation, le 8 octobre 1672, à l'abbé Pécoil, qui avait participé à la mission de l'ambassadeur de Nointel, avant de rentrer en France. Celui-ci la montra à Jacob Spon, qui la publia dans un ouvrage lui-même intitulé Relation de l'état présent de la ville d'Athè$n e s^{65}$. Babin devint, par la suite, le correspondant et l'informateur de Spon. Galland avait déjà rencontré Babin lors de son premier voyage à Smyrne ${ }^{66}$. Il ressort de sa correspondance ${ }^{67}$ que ce n'est qu'au cours de son troisième séjour dans cette ville (en mars 1680) qu'il commença à apprécier toutes les qualités du père jésuite. Il apparaît toutefois que la Relation de l'Isle de Tines n'était pas destinée à Galland, mais bien à Spon ${ }^{68}$. Babin y déclare en effet $\left(f^{\circ} 196\right)^{69}$ : «Tous ces employs m'ont empesché d'achever cette relation que vous m'avez demandée depuis deux années». En avril 1677, Galland se trouvait à Paris et il ne devait repartir en Orient qu'en octobre de la même année. De plus, ses contacts avec Babin étaient réduits à leur plus simple expression jusqu'au moment où Galland le côtoya plus longuement en 1680. Mais bien plus que

${ }^{63}$ Moreau de Mautour a ajouté, à côté du titre ( $\left.\mathrm{f}^{\circ} 185\right)$ la mention «par le P. Babin jesuite».

${ }^{64}$ Il naquit à Fontenay-le-Comte le 22 août 1634, entra au noviciat dès mars 1654 et se rendit en Grèce en 1669. Il revint en France en 1694 et rendit l'âme à La Rochelle le 3 juin 1699. V. C. Sommervogel, Bibliothèque de la Compagnie de Jésus. Bibliographie. Tome I, col. 744-5 et tome VIII, col. 1719.

${ }^{65}$ Paru à Lyon en 1674. Le texte de Babin fut à nouveau édité, par le comte de Laborde, cette fois, dans son ouvrage intitulé Athènes aux XV $V^{e}, X V I^{e}$ et $X V I I^{e}$ siècles (Paris, 1854,2 vol.).

${ }^{66}$ Abdel-Halim, Antoine Galland, p. 71, note 24.

67 «Estant arrivé en cette ville il y a 8 jours, déclare-t-il dans une lettre adressée à Spon le 3 avril 1680, j'eus soin d'abord d'aller voir le P. Babin, ayant appris qu'il y avoit desjà du temps qu'il estoit retourné de Tinos». V. M. Abdel-Halim, Correspondance, pp. $139-40$

${ }^{68}$ M. Couvreur et D. Viviers (Jacob Spon, à travers un manuscrit inédit, p. 255) émettent l'hypothèse que ce sont les quatre lettres de son nom qui se cachent derrière les quatre astérisques.

${ }^{69}$ On trouvera une transcription de l'introduction et de la fin de cette relation à l'annexe 3. 
tout cela, un des éléments décisifs qui nous poussent à penser que le destinataire de cette relation était bien Jacob Spon réside dans une autre lettre $^{70}$ de l'éditeur parisien Barbin qu'il adressa à ce dernier le 20 juillet 1679 , c'est-à-dire un mois, jour pour jour, après celle qu'il lui avait envoyée et dans laquelle il mentionnait le projet de joindre la traduction de Galland de l'État présent à sa Smyrne ancienne et moderne (annexe 1) ${ }^{71}$. Barbin y déclare: "Je vous remercie, Monsieur, de l'offre que vous me faites de cette petite relation du P. Babin pour joindre à la Smirne de M. Gallant. Comme la diversité plaist dans les livres et surtout dans les relations, je crois que cela ne sera pas un petit ornement au livre, puis quelle a vostre aprobation». On voit ici, à nouveau, le rôle important d'intermédiaire joué par le médecin lyonnais: offrant, dans un premier temps, la traduction que Galland fit de l'ouvrage de Joseph Georgirènes, que Barbin songe à annexer à sa Smyrne ancienne et moderne, il lui propose la relation de Babin qu'il avait dû recevoir entre-temps, c'est-à-dire dans l'intervalle qui s'étend entre le 15 juin et le 15 juillet. Les propos de Barbin ne laissent planer aucun doute quant au fait que l'idée de joindre cette dernière relation aux ouvrages de Galland venait bien de Spon. On comprend mieux pourquoi il est techniquement inconcevable de penser que cette relation ait eu pour destinataire Galland, qui se trouvait pour lors à Smyrne. Ce dernier aurait dû la réexpédier à son ami Spon dans un laps de temps inférieur à deux mois, en tenant compte du trajet Tines (avril)-Smyrne, Smyrne-Lyon, Lyon-Paris (juillet). Enfin, tout ce qui précède est corroboré par la lettre que Galland adressa de Smyrne à Spon, le 14 avril 1680. Il y précise, en guise de post-scriptum: «Le Père Babin qui vous a écrit il n'y a que peu de jours vous salue seulement par mon moien. Il m'a lu une bonne partie de sa Relation de Tinos où il y a de bonnes choses $[\ldots]^{72} \gg$.

70 Nous transcrivons complètement cette lettre à l'annexe 5.

${ }^{71}$ V. G. E. Reed, op. cit., p. 66.

${ }^{72}$ V. M. Abdel-Halim, Correspondance, p. 146. Ajoutons encore, si besoin est, qu'une lettre de Babin adressée à Spon le 2 avril 1680 fait allusion à la Relation de l'isle de Tines que l'auteur dit lui avoir envoyée: «Pour ce qui est de la Relation de Tines, j'eusse bien souhaitté que vous en corrigeassiez et retranchassiez quelques choses, qui peut-estre, ne plaira pas, ou sera trop basse» (Bibliothèque Municipale de Lyon, ms. 1721, lettre 154). Cette lettre fut éditée dans son entier par H. Omont, Athènes au XVII siècle, dans Revue des Études Grecques 14 (1901), pp. 285-90. V. aussi M. Abdel-Halim, Correspondance, p. 140 (note 1). 
Barbin reçut bien la Relation de l'Isle de Tines comme en témoigne sa présence tout à la fin du manuscrit bruxellois, après la Smyrne ancienne et moderne et l'État présent. Nous pensons que Galland ne devait pas être au courant de cette nouvelle addition à son œuvre originale, pas plus qu'il ne semblait l'être pour la traduction de l'État présent. En tout cas, nous ne trouvons aucune mention, voire même allusion, à ce fait dans sa Correspondance. Toujours est-il qu'en récupérant le manuscrit qui avait été déposé chez Barbin, il en prit possession. On ignore dans quelle mesure Babin s'inquiéta de la publication de sa relation. Probablement s'attendait-il à la voir paraître, non pas indépendamment, mais en tant que partie d'un ouvrage, comme cela avait déjà été le cas pour sa relation de la ville d'Athènes.

Nous avons vu que le projet de publication de ces trois textes resta lettre morte. Cependant, nous ignorons ce qu'il advint aux manuscrits déposés chez Barbin et comment Galland les récupéra lors de son retour d'Orient en décembre 1688. L'hypothèse selon laquelle ce fut son ami et intermédiaire J. Spon qui les conserva doit être écartée: adepte de la Religion Réformée, ce dernier rendit son dernier souffle sur le chemin de l'exil sur lequel l'avait chassé la révocation de l'Édit de Nantes (décembre 1685$)^{73}$. On ne peut donc que conjecturer en cette matière, mais il semble bien que les manuscrits restèrent en dépôt chez Barbin. Galland allait encore avoir affaire à ce dernier pour la publication de la Bibliothèque orientale de d'Herbelot de Molainville, qui parut en $1697^{74}$. Enfin, Barbin décéda le 24 décembre $1698^{75}$.

${ }^{73}$ D'ailleurs, à titre d'exemple, Galland ne devait jamais remettre la main sur sa traduction du traité sur les pétrifications marines d'Agostino Scilla que Spon avait gardé. $V$. note 32 .

74 Galland avait été engagé par d'Herbelot à la fin de 1694 afin de l'assister pour préparer l'impression de cet ouvrage. L'auteur devait toutefois décéder un an plus tard. Galland s'attacha à veiller à la parution, à titre posthume, de la Bibliothèque orientale. Il en rédigea notamment la préface. Sur cet aspect de la vie de Galland, v. Abdel-Halim, Antoine Galland, p. 85 sqq. Sur la Bibliothèque orientale, v. H. Laurens, Aux sources de l'orientalisme, la «Bibliothèque orientale» de Barthélemi d'Herbelot, Paris, 1978, 103 p., où l'auteur étudie les sources mises à profit par d'Herbelot; J. Gaulmier, À la découverte du Proche-Orient: Barthélemy d'Herbelot et sa Bibliothèque orientale, dans Bulletin de la Faculté des Lettres de Strasbourg, 48e année, 1 (octobre 1969), pp. 1-6.

75 G. E. Reed, op. cit., p. 51. 
Toutefois, il ne fait aucun doute que Galland parvint à remettre la main sur ces textes: nous en voulons pour preuve les corrections et les ratures ajoutées surtout au texte de la Smyrne ancienne et moderne. Galland avait déjà procédé à certaines additions ${ }^{76}$ dès son retour de Smyrne en 1678, mais celles-ci avaient été inscrites sur des morceaux de papier indépendants ou sous forme de notes marginales. Les nombreuses ratures qui émaillent le texte datent, selon nous, de la période qui suivit son retour d'Orient en 1688. Cette hypothèse est corroborée par Galland luimême qui affirme avoir mis au net et retravaillé une partie de ses récits de voyages avant $1701^{77}$. Ses occupations au service de Nicolas-Joseph Foucault, à Caen, à partir de 1697, ses multiples travaux, dont la traduction des Mille et une nuits commencée en 1702 et dont le premier volume paraîtra en 1704, enfin sa nomination au Collège de France en 1709, allaient sans doute le distraire définitivement du projet de publication de ses relations de voyages.

\section{2. À la mort de Galland}

Peu avant de mourir, le 17 février 1715, Galland exprima ses dernières volontés sous forme de testament verbal à deux de ses collègues et

${ }^{76}$ V. supra pp. 13-14. D'autre part, Galland ajouta, à côté de son nom, le titre d'Antiquaire et Interprète des langues orientales. Hors, le titre d'Antiquaire du Roi ne lui fut officiellement attribué que le 1er septembre 1685, tandis qu'il se trouvait toujours en Orient. Ce fut grâce aux recommandations de son ami et mécène Jean Foy-Vaillant qu'il obtint ce titre et le salaire qui l'accompagnait à un moment où il vivait de durs moments (l'ambassadeur de Guilleragues, qui l'avait pris à son service, était décédé entre-temps). $V$. M. Abdel-Halim, Antoine Galland, p. 74. Ce n'est donc qu'après son retour en France, en décembre 1688, qu'il a, d'une part, pu récupérer son manuscrit, et d'autre part ajouter le titre en question.

On possède divers témoignages qui attestent que Galland tâcha de récupérer certains de ses textes qui n'étaient plus en sa possession. Ainsi tenta-t-il de remettre la main sur sa relation du voyage d'Alexandrie envoyée à Rainssant, et dont il avait perdu la minute dans le tremblement de terre à Smyrne en 1688. Celui-ci était décédé entre-temps, et on ne parvint pas à la retrouver dans ses papiers. V. M. Abdel-Halim, Correspondance, p. 363. Galland eut plus de chance avec un recueil de proverbes en grec vulgaire qu'il avait collectés et traduits en français durant son séjour en Orient et qu'il avait prêté à Jean FoyVaillant avant de repartir pour Constantinople en 1679. À la mort de Vaillant (1706), sa fille le trouva dans ses papiers et le rendit à Galland deux ans plus tard. Galland le récupéra donc après presque trente ans d'attente! V. H. Omont, Journal parisien, p. 28.

$77 \mathrm{~V}$. la note 54 supra. 
amis de l'Académie des Inscriptions. Celles-ci prévoyaient le legs de l'ensemble de ses manuscrits à la Bibliothèque du Roi, à quelques exceptions près ${ }^{78}$. Un inventaire des manuscrits conservés dans sa bibliothèque fut dressé, dès le surlendemain 19 février, par le bibliothécaire du Roi, Boivin ${ }^{79}$. Dans la première version de celui-ci, Boivin mentionne «deux petits volumes de relations ou journaux de ses voyages en Levant», ce à quoi il ajoute que le neveu de Galland, l'abbé Despréaux, souhaiterait les garder pour lui ${ }^{80}$. La seconde version fait toujours état de deux volumes de relations, mais n'évoque plus ce souhait ${ }^{81}$. Il n'est fait nulle part allusion à d'autres volumes de relations; ce qui peut paraître étonnant puisqu'à ce jour 5 volumes sont conservés ${ }^{82}$. On sait pourtant que le neveu de Galland, en dépit de ses prétentions, n'obtint que trois manuscrits qui ne correspondent en rien aux relations de voyages.

Nous ne pouvons de nouveau que conjecturer sur les raisons de cet oubli, mais il est évident que plusieurs volumes contenant les relations de voyages furent bien légués à la Bibliothèque du Roi ${ }^{83}$. Et nous vou-

${ }^{78}$ Un Dictionnaire historique et numismatique revint à l'Académie des Inscriptions, la traduction du Coran à l'abbé Bignon, et quatre textes au neveu de Galland, l'abbé Despréaux, qui reçut en outre une somme de six livres pour le dédommager d'éventuels ouvrages auxquels il aurait pu prétendre avoir droit. V. Abdel-Halim, Antoine Galland, pp. 137-143.

79 Cet inventaire est conservé à la Bibliothèque Nationale, archives du Département des manuscrits. Il a été complètement transcrit par H. Omont, Journal parisien, pp. 17-22 et à sa suite par Abdel-Halim, Antoine Galland, note 8 qui s'étend de la p. 138 à 143. Une autre version de cet inventaire, plus détaillée, fut retrouvée par Abdel-Halim (BnF, fonds latin, $\mathrm{n}^{\circ}$ 17174, ff. 45-47), ibid.

${ }^{80}$ V. H. Omont, Journal parisien, p. 19; M. Abdel-Halim, Antoine Galland, p. 139, en note, les numéros 1-2.

${ }^{81}$ V. M. Abdel-Halim, Antoine Galland, p. 143, $\mathrm{n}^{\circ}$ 12. Ils figurent cependant dans la liste des manuscrits qui pourraient être rejetés par l'héritier de Galland.

${ }^{82}$ Le volume conservé à Bruxelles, les deux volumes de la BnF (années 1672-3) et les deux autres à Munich (années 1679-80). Il semble que l'inventaire était loin d'être exhaustif. Ainsi, on ne trouve nulle mention des deux derniers volumes des Mille et une nuits qui furent pourtant publiés, à titre posthume, en 1717, après qu'ils eurent été remis à l'éditeur. Il en va de même pour le journal dit «parisien» (1708-1715), sa correspondance et bien d'autres textes encore.

${ }^{83}$ Sans doute les termes utilisés dans les deux listes dressées à la mort de Galland pour décrire ses ouvrages sont-ils à prendre dans un sens plus large, car dans une autre source un peu plus tardive qui fait mention de son œuvre manuscrit, il est question de deux porte-feuilles contenant la relation de ses voyages: «Mais ce ne sont pas là les seuls ouvrages qu'ait laissez M. Galland; on en a trouvé un plus grand nombre encore dans 
lons pour preuve irréfutable de cette affirmation le renseignement suivant. Pontchartrain, dans une lettre du 12 juin 1715 adressée à l'abbé de Louvois, surintendant des bâtiments, et à ce titre en charge de la Bibliothèque Royale, déclare: «Il paroist qu'on pourroit faire imprimer quelqu'un de ces manuscrits, en faisant corriger les traductions, et les mettre dans un plus beau françoys, et le Roy m'a dit à cette occasion que vous preniez la peine de les faire examiner, afin de voir ceux qu'il conviendroit de donner au public et qui mériteroient la peine d'estre imprimez, et ensuitte on pourroit les faire corriger par quelqu'un (comme le P. Le Sage) par rapport à la diction ${ }^{84} »$. Si le célèbre auteur de Gil Blas, Lesage, ne fut probablement pas contacté 85 , nous savons par contre que la première étape mentionnée par Pontchartrain (un examen préliminaire visant à séparer le bon grain de l'ivraie ${ }^{86}$ ) avait déjà eu lieu. Le Registre des ouvrages présentés à Monseigneur le Chancelier et des privilèges accordés ${ }^{87}$ fait bien référence à cet examen. Voici ce qu'il nous en dit: «Voyage fait en Levant, par Antoine Galland, plusieurs volumes. Présenté par xx, libraire à Paris ce 8 mai 1715. Distribué à M. Moreau de Mautour. Approuvé avec éloge le 5 juin 1715. Privilège général à xxx pr [lisez par] Gixans [?] le mercredi 5 juin $1715 »$.

ses papiers, et les plus considérables sont: une relation de ses voyages, en deux portefeuilles in $-4^{\circ}$, une Description particulière de la ville de Constantinople [...]». Gros de Boze, Histoire de l'Académie Royale des Inscriptions et Belles-Lettres depuis son établissement, avec les éloges des Académiciens morts depuis son renouvellement. Tome II, p. 46. Ces titres sont de nouveau cités dans le «catalogue des ouvrages de M. Galland» qui figure aux pp. 50-4.

Le terme «porte-feuille», moins restrictif que celui de «volume» employé dans les deux listes dressées à la hâte, permet une interprétation différente et ne laisse plus à penser avec certitude qu'il s'agissait des deux uniques volumes du Voyage fait en Levant, dont le titre, par ailleurs, n'apparaît pas explicitement.

${ }^{84}$ Lettre figurant dans les archives du département des manuscrits de la Bibliothèque Nationale. Elle est transcrite par H. Omont, Journal parisien, p. 23. Cet extrait est cité par M. Abdel-Halim, Antoine Galland, p. 144.

${ }_{85} \mathrm{Au}$ demeurant, son nom n'est qu'évoqué par Pontchartrain, et les manuscrits ne contiennent pas de trace de son écriture. V. M. Abdel-Halim, Antoine Galland, pp. 144 et $308-9$.

${ }^{86}$ Si tant est qu'on puisse parler d'ivraie dans la production de Galland.

${ }^{87} \mathrm{BnF}$, fonds fr., $\mathrm{n}^{\mathrm{0}} 21942$, p. 311 ( $\left.\mathrm{n}^{\mathrm{o}} 350\right)$. 
Ces renseignements sont encore corroborés par la note suivante figurant tout à la fin (p. 19988) du premier volume du Voyage fait en Levant (Munich, cod. gall. 727):

«J'ay leû et examiné, par ordre de Monseigneur Le Chancelier, plusieurs manuscripts compris sous le titre, de Voyages faits dans le Levant par Antoine Galand [sic]. Les relations et les mémoires d'un voyageur sçavant et curieux tel qu'estoit l'autheur, paroissent toujours très utiles par rapport aux mours et aux couthumes des peuples, aux descriptions des lieux, aux recherches historiques, dont il estoit si bien instruit. Ainsy j'ay cru que l'impression de ces Manuscripts seroit receüe du public avec une grande satisfaction.

fait ce $5^{e}$ may [raturé au profit de juin] 1715

Moreau de Mautour»

Moreau de Mautour, académicien et censeur royal ${ }^{89}$, précise donc bien qu'il eut entre les mains plusieurs manuscrits de relations de voyage dont le titre général était Voyages faits dans le Levant; ce qui est encore confirmé par la notice du Registre des privilèges déjà citée qui indique que sous ce titre figuraient plusieurs volumes. Contrairement à ce que pensait Abdel-Halim, il n'avait pas seulement reçu les deux volumes du Voyage fait en Levant, mais aussi d'autres relations ainsi que le prouve le manuscrit de Bruxelles, dont chaque folio fut paraphé par ce relecteur (sigle $m d m$ pour Moreau de Mautour), ainsi que celui de la relation de l'Histoire de l'esclavage d'un marchand de Cassis à Tunis ${ }^{90}$. Il est donc

${ }^{88}$ Cette note est citée par M. Abdel-Halim, Antoine Galland, p. 320 avec quelques erreurs, ce qui l'a mis sur une mauvaise voie. Elles sont sans doute imputables à l'édition du Voyage fait en Levant qui a été préparée par $\mathrm{Cl}$. Brigault dans le cadre d'un mémoire dactylographié sous la direction de Fr. Deloffre (Faculté des Lettres de Lyon) en 1962.

${ }^{89}$ Moreau de Mautour fut aussi auditeur à la chambre des comptes. Né en 1654, il rendit l'âme en 1737. Abdel-Halim, Antoine Galland, le cite en plusieurs endroits sous la forme erronée «Moreau de Mantour».

Par ailleurs, il est établi que Galland avait côtoyé Moreau de Mautour, tous deux ayant été membres de l'Académie des Inscriptions. Galland le cite à plusieurs reprises dans sa correspondance. V. M. Abdel-Halim, Correspondance, lettres CLXXXVIII, CCCVI, CCCX, CCCXII-XV (datées de 1702 et 1711).

${ }^{90} \mathrm{BnF}$, fonds fr., $\mathrm{n}^{\circ}$ 14963. Abdel-Halim, Antoine Galland, p. 308, note 37, avait remarqué que ce manuscrit portait le paraphe de Moreau de Mautour. Il n'a cependant pas 
clair que ces derniers faisaient partie du legs à la Bibliothèque de Louis XIV, même s'ils ne figurent pas dans l'inventaire dressé à la mort de Galland.

Malgré les propos élogieux du censeur royal et le privilège général accordé le 5 juin 1715 à un imprimeur qui n'est pas cité, les relations de voyages de Galland ne devaient, une fois de plus, pas être portées à la connaissance du public. L'abbé Bignon fut certainement la cause principale de leur maintien dans l'ombre. Grand ami de notre orientaliste, il semblait vouer plus d'admiration à un autre genre d'ouvrages, comme cette traduction du Coran que Galland entreprit et termina sur son instigation et dont il hérita par ailleurs. "On a eu raison, déclare-t-il dans une lettre à Gisbert Cuper, ami hollandais de Galland, de vous marquer qu'on songeoit à publier les Voyages de M. Galland: sçavoir s'ils seront bien receus du public, c'est ce dont je n'oserois vous répondre. De tous les morceaux qui m'en sont tombés entre les mains, je n'en ai trouvé que de très imparfaits; et il y a lieu de craindre que le reste n'ait pas été travaillé avec plus de soin, et plus d'exactitude. Que cela soit dit entre nous. Vous sçavez combien je l'estimois; et ses autres manuscrits, si jamais on les imprime, feront plus d'honneur à sa mémoire ${ }^{91}{ }$. Jugement sans appel d'un homme qui n'avait probablement pris la peine que de consulter une partie des manuscrits ${ }^{92}$. «Les morceaux qui lui sont tombés entre les mains» provenaient peut-être du Journal de 1672-1673, qui est rédigé au jour le jour, sans que notre érudit ait attaché une importance particulière au style; ce qui est loin d'être le cas pour la Smyrne ancienne et moderne et le Voyage fait en Levant. Ces deux ouvrages sont des textes aboutis, résultats d'un travail remis plusieurs fois sur le métier et basés sur les notes, presque télégraphiques, consignées jour après jour

fait le lien avec la note figurant dans le premier volume de la relation conservé à Munich et que nous venons de citer.

${ }_{91}$ Correspondance de Gisbert Cuper avec l'abbé Bignon, Bibliothèque royale de La Haye, ms. français $n^{\circ} 72 \mathrm{H} 7$, lettres de Cuper des 7 avril et 3 juin 1715. Cité par M. Abdel-Halim, Antoine Galland, pp. 319-20. On constate que ce jugement fut exprimé deux jours avant les propos hautement élogieux de Moreau de Mautour.

${ }_{92}$ L'abbé Huet déclarait le 11 mars 1701, dans une lettre adressée à Galland «Pour la relation de vos voiages, je vous répons du succez, et en particulier de mon application et de mon plaisir à la lire. Aucune ne m'échappe. Jugez avec quelle avidité, j'en lirai une utile, et agréable en tant de matières». V. M. Abdel-Halim, Correspondance, p. 367. 
dans le Journal. Smyrne ancienne et moderne avait d'autre part été conçue pour la publication et fut soumise à un éditeur. Comment Bignon, s'il l'avait lue, pouvait-il la juger imparfaite?

Peu importent les motivations de l'abbé puisque le résultat est là: les relations de voyages retournèrent dormir sur les rayons de la Bibliothèque Royale pendant quelques décennies avant qu'un compatriote n'éprouve le souhait de les exhumer ${ }^{93}$. Nul doute, cependant, que si l'ensemble des relations de voyages de Galland avait paru de son vivant même, ou de manière posthume, comme ce devait être le cas, on aurait pu écrire pour son épitaphe «Nomen sibi fecit eundo» (Il se fit un nom en voyageant), à l'instar de son contemporain Jean Chardin ${ }^{94}$.

\section{La période intermédiaire}

Il fallut attendre qu'un autre Picard, orientaliste de surcroît, LouisMathieu Langlès, s'intéresse, à la fin du XVIII ${ }^{\mathrm{e}}$ s., aux manuscrits laissés par Galland. Un bref coup d'œil sur sa bibliographie nous indique qu'il consacra une grande partie de son temps à l'édition de relations de voyages. Nous ne citerons, à titre d'exemple, que la prestigieuse édition qu'il donna des Voyages de Jean Chardin ${ }^{95}$. Il publiera effectivement l'Histoire de l'esclavage d'un marchand de Cassis à Tunis ${ }^{96}$ et le Voyage de la Perse dans l'Inde pendant les années 845, 846, 847 et 848 de l'Hégire ${ }^{97}$, tous deux de la main de Galland. Il marquera également

93 Abdel-Halim, Antoine Galland, p. 320, note 94, émet l'hypothèse qu'ajoutee aux réticences de l'abbé Bignon la publication, à titre posthume en 1717, par l'imprimerie royale de la Relation d'un voyage du Levant fait par ordre du Roy de Joseph Pitton de Tournefort, qui traitait de sujets assez similaires à ceux évoqués par Galland dans ses propres relations, mit un point final au projet. Nous lui objecterons que dans le cas de la Smyrne ancienne et moderne les quelques pages consacrées par Tournefort à la ville de Smyrne ne tiennent pas la comparaison avec la monographie que lui consacra Galland. Nous verrons infra que cet ouvrage peut être considéré comme la meilleure description de cette ville d'Asie Mineure au XVII ${ }^{\mathrm{e}} \mathrm{s}$.

94 V. Dirk Van der Cruysse, op. cit., p. 332.

95 Parue en 1811 en 10 volumes, un atlas et plus de 2000 notes. 59.

96 Dans Le magasin encyclopédique de 1809, tome I, pp. 268-328 et tome II, pp. 18-

${ }^{97}$ Langlès se rendit coupable de plagiat en le publiant sous son nom. Il parut à Paris, an VI, dans le tome II de la Collection portative des voyages, pp. XXV-CXVII. $V$. sur la question, M. Abdel-Halim, Antoine Galland, p. 238. 
un intérêt certain pour le Voyage fait en Levant et l'État présent qu'il se proposait de publier. Il ne donna toutefois pas suite à son projet. Dans l'article consacré à Galland dans la Biographie universelle (tome XVI, p. 352, numéros XI et XII), Jourdain précise que les manuscrits de ces deux textes appartenaient à Langlès! Nous avons la chance de posséder le catalogue de sa bibliothèque qui fut mise en vente en $1825^{98}$ : le numéro 4351 (p. 531) est intitulé Voyage d'Ant. Galland dans le Levant, en 1679 et 1680, et le 4352 (pp. 531-2) porte le titre État présent des isles de Samos, de Nicarie, Pathmos, et du Mont Athos; par Joseph Georgine, archevêque de Samos, et trad. du grec vulgaire en franç., par le même Galland. S'agit-il des manuscrits aujourd'hui conservés à Munich? Il semble bien que oui en ce qui concerne le manuscrit de l'État présent, puisque la notice du catalogue de la bibliothèque de Langlès correspond mot pour mot au titre qui figure dans le manuscrit ${ }^{99}$. Quant au Voyage fait en Levant, le manuscrit de la relation de ce voyage ayant appartenu à Langlès est décrit comme un petit in-folio de 30 feuillets, alors que le texte autographe à Munich tient en deux volumes. Mais faut-il en conclure, comme le fit Abdel-Halim ${ }^{100}$, qu'il ne s'agit que d'une copie due à Langlès en vue de l'édition? Nous ne le pensons pas, car l'auteur du catalogue insiste bien dans sa préface (p. XVII) sur la présence de trois manuscrits autographes de Galland ${ }^{101}$. Par ailleurs, les deux volumes du Voyage fait en Levant conservés à Munich porte l'écriture de Langlès ${ }^{102}$. Légués à la Bibliothèque Royale à la mort de leur auteur, on constata leur disparition en $1800^{103}$. Sans pouvoir l'affirmer

98 Catalogue des livres, imprimés et manuscrits, composant la bibliothèque de feu M. Louis-Mathieu Langlès [...] dont la vente se fera le jeudi 24 mars 1825 et jours suivants, 6 heures de relevée, Maison Silvestre, rue des Bons-Enfants, $n^{\circ}$ 30. Paris (J.-S. Merlin), XVIII-558 p.

99 À la seule exception de deux mots (en franç.) qui ont pu être rajoutés par la personne qui a rédigé la notice dans le catalogue de la bibliothèque de Langlès.

100 Antoine Galland, p. 321 (note 97). L'exemplaire du catalogue de la bibliothèque de Langlès que nous avons consulté indique bien «ms. autographe», tandis que AbdelHalim, en citant le passage, indique «Ms. Copie»!

${ }^{101}$ Le troisième manuscrit autographe de Galland est le no 4353: Biographie arabe, persane et turque, extraite et traduite de divers auteurs orientaux, par Ant. Galland. Ms. autographe, avec sa mise au net. Il peut fournir la matière d'un vol. in-8.

102 V. infra.

103 V. M. Abdel-Halim, Antoine Galland, p. 321 (note 97). 
avec certitude, nous pensons qu'ils ne furent pas détournés par Langlès, sciemment ou non, même si, après tout, il est attesté qu'il arracha des pages d'un autre manuscrit de Galland ${ }^{104}$. En effet, ces disparitions semblent s'être produites à de multiples reprises, sans qu'elles lui soient toutes imputables. Ainsi, le manuscrit du Journal de 1672-1673, qui intégra les collections de la Bibliothèque du Roi sous la cote 10551 à la mort de Galland, disparut à un moment donné pour réapparaître en 1893 dans la vente des manuscrits du baron Taylor, où il fut acquis par la Bibliothèque Nationale ${ }^{105}$.

Mais il reste une possibilité de disculper Langlès. Dans le ms. cod. gall. 727 de Munich, qui contient le premier volume du Voyage fait en Levant (année 1679), on peut lire l'inscription suivante sur le folio en tête: Cabinet \& manuscr. en dépendans appart. à Louis Sr. Delatour, Secrétaire du Roy, du Grand Collège, \&c. Ajoutons à cette information que dans la notice biographique de Galland que publia Jourdain dans la Biographie universelle, ce dernier mentionne, parmi ses ouvrages, une Relation de ses voyages ${ }^{106}$. Il précise que le manuscrit avait été la possession de Brotier, «qui y attachait une grande importance». Il apparaît enfin, comme nous le verrons, que la Relation des voyages de Galland que possédait Brotier et le manuscrit du Voyage fait en Levant conservé à Munich ne font qu'un. Mais quel lien y a-t-il entre Delatour et Brotier?

Gabriel Brotier ${ }^{107}$ (Tannay, 5 septembre 1723 - Paris, 12 février 1789) avait embrassé l'habit ecclésiastique en entrant chez les Jésuites. Ayant acquis une solide connaissance des langues anciennes et doté d'un intérêt certain pour des domaines aussi scientifiques que divers, il fut contraint, lorsque l'ordre des Jésuites fut supprimé, de trouver refuge chez une personne dont il avait gagné l'amitié par le biais d'un goût commun pour l'étude. L'ami en question, c'était Delatour! Ce dernier

104 V.ibid., p. 237.

Soulignons également qu'à partir d'août 1792, Langlès eut un accès aisé aux manuscrits de la Bibliothèque Nationale, puisque c'est à cette date qu'il obtint une place de sous-garde à la section des manuscrits. V. Biographie universelle, ancienne et moderne. Supplément. Tome LXX (Paris: Michaud, 1842), p. 191.

${ }_{105}$ V. M. Abdel-Halim, Antoine Galland, p. 311 (note 49). Une copie soigneuse de ce journal est conservée à la Bibliothèque de l'Arsenal (ms. 2743).

${ }^{106}$ Biographie universelle, tome XVI (1816), p. 352 ( $\mathrm{n}^{\circ}$ VIII).

107 Biographie universelle, tome VI (1811), pp. 38-9. 
doit être identifié comme étant Louis-François Delatour (Paris, 6 avril 1727 - Paris, 9 novembre 1807). Secrétaire du roi, il fut aussi imprimeur-libraire à Paris, profession qu'il devait abandonner vers la fin de sa vie afin de se consacrer exclusivement à ces centres d'intérêt: la littérature et les arts, et plus particulièrement tout ce qui touchait la Chine ${ }^{108}$. Brotier devait rester à son service de 1763 jusqu'à sa mort en 1789 et son hôte allait même publier un de ses ouvrages majeurs ${ }^{109}$. Nous ignorons comment Brotier mit la main sur le Voyage fait en Levant. Le subtilisa-t-il à la Bibliothèque Royale ${ }^{110}$ ou peut-être l'acquit-il auprès d'une tierce personne qui avait commis le forfait elle-même? Dans l'état actuel de nos connaissances, ces interrogations ne resteront que conjectures. Mais nous possédons un élément qui nous permet d'affirmer que Brotier en était le propriétaire avant 1783. Dans un Mémoire sur le tableau de Ialysus, peint par Protogène, et sur la peinture à plusieurs enduits, lu à l'Académie des Inscriptions et Belles-Lettres en date du 18 mars $1783^{111}$, Brotier fait référence au troisième voyage de Galland, donne des détails, tire des informations ${ }^{112}$ et procède à une citation du Voyage fait en Levant qu'il nomme explicitement: «Ici je vais rapporter ses propres expressions, que je tire, sans y changer un seul mot, du manuscrit original et authentique du voyage ${ }^{113} »$. Brotier se garde bien de dire quoi que ce soit sur l'éventuel propriétaire du manuscrit.

Après la mort de Brotier, les deux volumes du manuscrit en question passèrent entre les mains de son ami et hôte Delatour. Sans doute en

108 Sur ce personnage, v. Biographie universelle, tome X (1813), p. 667.

109 L'ouvrage qui est connu comme étant le Tacite de Brotier (Corn. Taciti opera, recognovit, emendavit, supplevit, explecavit..., 4 vol.). Delatour le publia en 1771. V. Biographie universelle, tome VI, p. 38.

110 Soulignons que Brotier fut le dernier bibliothécaire du Collège de Louis-le-Grand, et qu'à ce titre il eut peut-être un accès plus aisé aux manuscrits conservés à la Bibliothèque du Roi.

${ }^{111} V$. Mémoires de littérature, tirés des registres de l'Académie des Inscriptions et Belles-Lettres, depuis l'année MDCCLXXX, jusques et compris l'année MDCCLXXXIV. Tome XLVI, Paris, 1793, pp. 463-76. Je remercie Jean Letrouit pour cette information.

112 Il fait notamment mention de plusieurs statues portant des inscriptions grecques. On en retrouvera le passage dans le ms. de Munich, cod. gall. 728, pp. 16-9.

113 Mémoires de littérature, tirés des registres de l'Académie des Inscriptions et Belles-Lettres, depuis l'année MDCCLXXX, jusques et compris l'année MDCCLXXXIV. Tome XLVI, pp. 469-70. Cette citation correspond au texte figurant dans le ms. de Munich, cod. gall. 728, pp. 19-23. 
novembre 1791, comme semble l'indiquer une inscription ajoutée dans le coin supérieur gauche d'un des feuillets du deuxième volume du Voyage fait en Levant ${ }^{114}$.

Qu'advint-il des deux manuscrits du Voyage fait en Levant à la mort de Delatour? La bibliothèque et le cabinet de cet amoureux des arts et des lettres furent vendus en deux parties, peu de temps après sa mort $(1807)^{115}$. Lors de la première vente, plusieurs manuscrits de Galland furent offerts: 1) Les contes et fables indiennes de Bidpay et de Lokman, traduit d'Ali Tcheleby Ibn Saleh, auteur turc, par A. Galland (troisième partie, fol., manuscrit, cart. Copie moderne)116; 2) Voyages d'Ant. Galland en Levant, en 1679 et 1680 (2 vol. in-4 , cart. Manuscrit) ${ }^{117}$; 3) Catalogue des Histoires arabes, persanes et turques (tiré de la Bibliothèque Orientale de Mustapha Hadgi Kalfa), traduit de l'arabe par A. Galland, Constantinople, 1682 (manuscrit) ${ }^{118}$. Ces trois manuscrits furent acquis par L.-M. Langlès, qui était aux premières loges puisqu'il fournit des renseignements pour la rédaction d'un des deux catalogues

114 Munich, cod. gall. 728, $\mathrm{f}^{\circ}$ en tête non numéroté (4): 9b [= novembre] 1791.

115 Premier catalogue des livres, la plupart précieux, du cabinet de feu M. L.-F. Delatour, ancien imprimeur-libraire et secrétaire du roi. Paris: Tilliard Frères et J.-G. Merigot, avril-mai 1808, 80 p. (404 lots). Un exemplaire de ce catalogue de vente est conservé à la Bibliothèque Royale Albert Ier, cote VH 21.643A4.

Second catalogue des livres, des ouvrages chinois, tartares, etc., tant manuscrits qu'imprimés, dessins, gravures et peintures à gouache, etc., exécutés à la chine, du cabinet de feu M. L.-F. Delatour, ancien-imprimeur et secrétaire du roi. Tilliard Frères et J.G. Merigot, janvier 1810, 185 p. (1408 lots). Un exemplaire de ce catalogue de vente est conservé à la Bibliothèque Royale Albert Ier, cote VH 21.666A1.

116 Premier catalogue..., p. 38, n 191. Sur ce texte, v. M. Abdel-Halim, Antoine Galland, p. 180 sqq. Galland traduisit bien le texte en question. Le manuscrit en est conservé à la $\mathrm{BnF}$, fonds fr., $\mathrm{n}^{\circ}$ 6133. Le même texte fut traduit par Julien-Claude Galland, neveu d'Antoine, qui fut drogman à Constantinople. V. sur lui Biographie universelle, tome XVI (1816), p. 352. Le manuscrit qui faisait partie de la collection de Delatour semble être de la main de l'homonyme d'Antoine Galland. La description qui en est donnée dans le catalogue de vente de la bibliothèque de Langlès ( $v$. infra) fournit en effet un renseignement capital: «Moi Galland, ai traduit les 31 feuillets de mon écriture qui suivent et je suis sûr de ma traduction faite en 1736 [!]». Ce manuscrit et une copie sont conservés à la $\mathrm{BnF}$, fonds fr., $\mathrm{n}^{\mathrm{o}} 24277$ et fonds fr. n. a., $\mathrm{n}^{\circ} 6833$.

117 Premier catalogue..., p. 45, $\mathrm{n}^{\circ} 231$.

118 Premier catalogue..., p. 66, no 340. Le manuscrit est conservé à la BnF, fonds fr., $\mathrm{n}^{\mathrm{o}} 6131$ ainsi qu'une copie, également autographe et légèrement remaniée, sous la cote 6130. V. sur cette traduction M. Abdel-Halim, Antoine Galland, pp. 163-4. 
de vente en question ${ }^{119}$. On comprend ainsi mieux comment Jourdain pouvait annoncer en $1816^{120}$ que Langlès possédait le manuscrit de la Relation d'un voyage fait à Constantinople en 1679 et 1680 et qu'il se proposait de le publier. À la mort de Langlès, sa bibliothèque suivit le même chemin que celle de Delatour. Le catalogue de vente de celle-ci mentionne bien non seulement le Voyage fait en Levant, mais également le manuscrit des Contes et fables de Bidpay et de Lokman, ainsi que celui du Catalogue des Histoires arabes, persanes et turques, auquel il faut ajouter un des manuscrits de l'État présent des îles de Samos... qui fait ici son apparition pour la première fois ${ }^{121}$.

L'heureux acquéreur de certains de ces manuscrits ${ }^{122}$ est connu: il s'agit d'Étienne Quatremère. Après son décès, sa bibliothèque fut acquise, dans sa totalité, par la Bibliothèque Royale de Munich, un peu avant 1858. Devant le grand nombre de doubles que la collection de Quatremère comportait, le conservateur en chef de cette bibliothèque décida de procéder à la vente de ceux-ci ${ }^{123}$. Bien évidemment, aucun des

119 Second catalogue..., p. 4: «Nous devons à l'amitié et à la complaisance de MM. de Tersan et Langlès d'avoir bien voulu nous donner les renseignements nécessaires sur les ouvrages chinois, tartares, etc.». Ce fut sans doute au cours de ces ventes que Langlès acquit également des manuscrits provenant de Brotier ( 6 cartons) qui se retrouvèrent dans la vente de sa bibliothèque en 1825. Catalogue des livres, imprimés et manuscrits, composant la bibliothèque de feu M. Louis-Mathieu Langlès, p. 532 sqq. ( $\mathrm{n}^{\circ}$ 4356). H. Omont précise (Missions archéologiques, vol. I, p. XVI) que les papiers Brotier acquis par Langlès et mis en vente à sa mort étaient conservés en la bibliothèque des PP. Jésuites, située rue Lhomand à Paris. Depuis lors, le fonds Brotier a été transféré aux Archives des Jésuites de France à Vanves.

${ }^{120}$ Biographie universelle, tome XVI (1816), p. 352 ( $\mathrm{n}^{\circ}$ XI).

121 Catalogue des livres, imprimés et manuscrits, composant la bibliothèque de feu M. Louis-Mathieu Langlès. Respectivement pp. 531-2, numéros 4350 (Contes et fables), 4351 (Voyage), 4352 (État présent) et 4353 (Catalogue ici décrit Biographie [sic] arabe, persane et turque, extraite et traduite de divers auteurs orientaux par Ant. Galland). Plusieurs de ces textes n'ont pas attiré l'attention de M. Abdel-Halim.

${ }_{122}$ Ceux du Voyage fait en Levant et de l'État présent.

${ }^{123} \mathrm{La}$ vente se fit en quatre étapes selon un classement par matières. La Bibliothèque Royale Albert Ier possède le catalogue de la première vente (cote VI 88225 A217). En voici les références: Catalogue d'une collection de livres précieux et importants provenant pour la plupart de la bibliothèque de feu M. Étienne Quatremère de l'Institut. Rédigé par M. Ch. Halm, conservateur en chef de la Bibliothèque Royale de Munich. Première partie: Numismatique, archéologie, épigraphie, art moderne dont la vente aura lieu à Paris le jeudi 25 novembre 1858 et jours suivants. À sept heures précises du soir, Maison A. Franck, rue Richelieu, 67. Par le ministère de $\mathrm{M}^{\mathrm{e}}$ Boulouze, commissaire-priseur. 
manuscrits n'était en double et ils entrèrent tous au département ad hoc où nous avons pu les consulter ${ }^{124}$.

Si le voile du mystère est levé pour l'histoire des deux volumes du Voyage fait en Levant, il nous reste à élucider comment le manuscrit bruxellois, contenant les autographes de la Smyrne ancienne et moderne et de l'État présent et la lettre de Babin, qui entra à la Bibliothèque du Roi, disparut à son tour. Nous ne disposons malheureusement d'aucun élément probant. On peut supposer qu'il fut également «emprunté» par un lecteur indélicat, mais dans ce cas, il ne doit pas avoir suivi le même chemin que le Voyage fait en Levant (Brotier — Delatour — Langlès Quatremère) puisqu'il ne refait surface à aucun moment, au contraire d'autres manuscrits de Galland. On sait toutefois qu'il passa entre les mains de Langlès ${ }^{125}$, étant donné les nombreuses notes de sa main qui y figurent ${ }^{126}$. Le manuscrit bruxellois ne contient, malheureusement, aucun indice (ex-libris ou marque de propriété) qui nous permette de retracer son histoire dans l'intervalle qui va de la seconde moitié du $\mathrm{XVIII}^{\mathrm{e}}$ s. au 12 août 1912, date de son entrée à la Bibliothèque Royale Albert $\mathrm{I}^{\text {er }}$ de Bruxelles, après avoir été acheté chez les libraires Burgersdijck et Niermans à Leiden. Le catalogue de ces libraires ne nous

52 p. La raison de la mise en vente d'une partie de la bibliothèque de Quatremère est donnée en p. II.

${ }^{124}$ Voyage fait en Levant, cod. gall. 727-728; État présent, cod. gall. 751.

125 Le fait qu'il n'apparaisse pas dans le catalogue de la bibliothèque de Langlès ne prouve rien. Ainsi la Bibliothèque de l'Université de Liège possède le manuscrit (ms. W 108) d'une Grammaire persane rédigée par Langlès à l'intention des étudiants de l'École des Langues Orientales, dont il avait été le fondateur et le directeur. Ce manuscrit ne figure pourtant pas dans le catalogue de sa bibliothèque mise en vente à sa mort.

126 Ses notes sont à la fois visibles dans le manuscrit bruxellois et dans ceux du Voyage fait en Levant conservés à Munich. Dans certains cas, il s'est attaché à recopier un texte initial qui était devenu proprement illisible à la suite des corrections apportées par Galland, Moreau de Mautour et finalement lui-même, utilisant soit des morceaux de papier attachés au manuscrit par un fil ou un point de colle, soit des feuilles approximativement du même format que celles du manuscrit. Ces ajouts ne portent pas le paraphe de Moreau de Mautour, ce qui atteste bien qu'ils sont postérieurs à 1715. Le travail d'édition de Langlès est plus visible dans les deux volumes munichois, où il eut recours à des symboles pour les corrections portées en marge ou sur un feuillet. On remarque également que pour certaines notes marginales d'Antoine Galland, Langlès souhaitait les faire apparaître en notes de bas de page, les faisant précéder de la mention adéquate (note de bas de page) et d'une lettre de l'alphabet pour la numérotation. 
fournit aucun détail déterminant ${ }^{127}$. Toutefois, nous sommes en droit de penser que le manuscrit était arrivé aux Pays-Bas bien avant cette date. En effet, le papier employé pour les pages de garde ( $f^{\circ} 1$ et celui qui le précède), au moment où le manuscrit reçut la reliure actuelle ${ }^{128}$, porte un filigrane représentant un homme à cheval sur un piédestal comprenant l'inscription «Prins Willem De Vijfde» (Prince Guillaume V) ainsi que le nom D \& C Blauw. Dirk et Cornelis Blauw ${ }^{129}$ produisirent du papier dès le début du XVIII ${ }^{\mathrm{e}}$ siècle, à un moment où le papier hollandais était de plus en plus apprécié sur le marché international, et particulièrement en France ${ }^{130}$. On a retrouvé leurs marques dans des manuscrits et des imprimés qui vont de 1733 à $1827^{131}$. Le filigrane au cavalier royal, dans lequel il faut voir Guillaume V (1748-1806), apparaît pour la première

127 Catalogue de vente de MM. Burgersdijck et Niermans, Leiden, 1910, vente du 1423 novembre 1910, 258 p.: Catalogue des bibliothèques de feu M. F. F. C. Fischer, docteur en philologie classique et recteur du gymnase réformé à Arnhem, M. F. v. Rijsens, historien et inspecteur des écoles à Alkmaar, M. N. A. Cramer, professeur d'histoire au gymnase à Zwolle, M. R. Oort, pasteur de l'église réformée à Ruurloo avec la bibliothèque importante d'un ancien professeur de droit et plusieurs autres successions. Exemplaire conservé à la Bibliothèque Royale Albert Ier sous la cote VI 87792 A30.

La notice du manuscrit de Galland figure à la p. 89 ( $\left.\mathrm{n}^{\circ} 1441\right)$ : «Manuscrits du célèbre orientaliste et numismate français Antoine Galland, 1646-1715. I. Voyage qui comprend la description et l'Etat ancien et moderne de Smyrne. II. Estat présent des îles de Samos, Nicarie, Patmos et du Mont Athos, par Joseph Georgerine, archevêque de Samos, trad. du grec vulgaire par Ant. Galland, 1679. Dans le même volume: Relation de l'Isle de Tines par le père Rrabiri (ou Rabier, jésuite) en 1679. En 1 vol. avec figures, $4^{\circ}$, veau. Ces mss. originaux, surtout ceux de Galland, sont fort intéressants. Ils ont été sans doute destinés pour être publiés ce qui prouve les nombreuses altérations et additions dans le texte. Ils portent à la fin les mots: Lu et examiné avec la signature Moreau de Mautour».

On ignore cependant de quelle bibliothèque, parmi toutes celles mentionnées sur la page de couverture, le manuscrit provenait.

128 Tout porte à croire que le manuscrit avait déjà reçu une reliure à la mort de Galland; en tout cas, avant le travail de relecture de Moreau de Mautour, terminé le 5 juin 1715. Le $\mathrm{f}^{\circ} 6$ nous en fournit la preuve irréfutable: dans une note marginale de la main de Galland, plusieurs mots ont été rognés. Le fait que Moreau de Mautour a recopié les mots dont une partie avait disparu montre clairement que le manuscrit avait été rogné avant de lui être transmis.

${ }^{129}$ Cornelis était le fils. Son père s'était associé à lui en 1750. Il devait décéder en 1762, tandis que son fils vécut jusqu'en 1782. $\mathrm{V}$. R. Gaudriault, Filigranes et autres caractéristiques des papiers fabriqués en France aux XVII et XVIII ${ }^{e}$ siècles, p. 51.

${ }^{130}$ Ibid., p. 50.

131 V. W. A. Churchill, Watermarks in paper in Holland, England, France, etc, in the XVII and XVIII centuries and their connection, p. 13. R. Gaudriault, op. cit., p. 51, a relevé leurs marques dans des manuscrits et des imprimés français datés de 1749 à 1788 .

Journal Asiatique 289.1 (2001): 1-66 
fois en $1753^{132}$; ce qui tendrait à montrer que le manuscrit bruxellois reçut sa reliure actuelle après cette date. Il reste impossible, cependant, de déterminer avec certitude, sur base de ce simple indice, si la reliure eut lieu en France ou aux Pays-Bas, indiquant par là le lieu de sa conversation à ce moment-là, puisque le papier hollandais était exporté un peu partout en Europe à cette époque ${ }^{133}$. Par ailleurs, il est certain qu'il se trouvait encore en France jusqu'à la mort de Langlès, en 1825, puisque le manuscrit porte son écriture.

\section{Destinataires De la SMYRNE ANCIENNE ET MODERNE}

Galland fait débuter son ouvrage par le mot «Messieurs», mais n'en dit pas plus. Pour pouvoir mettre des noms sur ces destinataires de la Smyrne ancienne et moderne, il faut nous tourner, de nouveau, vers un ouvrage similaire, d'ailleurs rédigé peu de temps après son voyage à Smyrne et pour lequel nous possédons plus de détails: le Voyage fait en Levant, dont les années 1679-1680 sont conservées.

Cette relation de voyage se compose de trois longues lettres adressées à l'abbé Pierre Cureau de la Chambre. Galland avait fait sa connaissance lors de son retour du premier voyage en Orient en 1675. Cet abbé, qui possédait d'excellentes relations dont il n'hésitait pas à faire profiter ses amis, notamment pour faire imprimer leurs travaux, appréciait particulièrement les récits de voyages. Il n'est donc pas étonnant que Galland lui ait dédié la relation de son troisième voyage en Orient. Toutefois, nous savons qu'il en réservait la primeur à son ami J. Spon, auquel il envoyait les lettres préalablement, afin que celui-ci les lise avant de les expédier à leur vrai destinataire ${ }^{134}$. Il n'est peut-être pas inintéressant, à

132 R. Gaudriault, op. cit., p. 54. W. A. Churchill, op. cit., p. 28, donne la durée d'emploi de ce filigrane entre 1762 et 1796 . Il le reproduit à la planche CXXXIX, où il apparaît sous une forme différente: le cavalier est tourné vers la droite et les mots Prins Willem sont abrégés en P. W. Pour la datation, il vaut mieux tenir compte de la donnée fournie par R. Gaudriault, dont l'ouvrage est basé sur des recherches plus récentes.

${ }^{133}$ MM. Couvreur et Viviers estiment, arbitrairement, que le manuscrit était bien en Hollande dès le XVIII ${ }^{\mathrm{e}}$ siècle, se basant sur le pays de production du papier en question. $V$. M. Couvreur et D. Viviers, Jacob Spon, p. 248.

134 Abdel-Halim, Antoine Galland, p. 318 (note 83), évoque le fait que Spon les faisait recopier dans le but de les faire circuler dans leur cercle d'amis, mais aussi probablement pour les faire imprimer. Toutefois, nous n'avons trouvé aucune preuve de cela dans la 
ce stade, de signaler comment Galland procédait pour la rédaction de ses relations. Les événements étaient notés par lui, au jour le jour, dans un journal, ou mémoire, sur lequel il se basait pour ensuite rédiger les lettres en question. C'est ainsi que la première lettre, datée de Milo le 1er novembre 1679, ne fut expédiée à l'abbé de la Chambre que le 3 avril 1680, la seconde datée également de Milo le 16 mars 1680 lui fut envoyée le 14 avril de la même année, et enfin la troisième lettre, qui est du 1 novembre 1680, fut écrite lors de son arrivée à Constantinople le 3 octobre. Galland en gardait une copie pour lui-même ${ }^{135}$; ce qui lui servit probablement pour rédiger la version définitive qui est aujourd'hui conservée à Munich. Cette méthode semblait assez fréquente à l'époque pour les relations de voyages ${ }^{136}$.

correspondance conservée, celle-ci nous montrant seulement que Galland laissait ouvertes les lettres destinées à l'abbé de la Chambre afin de permettre à son ami de les lire, comme on le voit ci-après.

Dans une lettre adressée de Smyrne à Spon, le 3 avril 1680, Galland déclare: «De plusieurs lettres que j'écris à Paris, je ne renferme que celle de Mr l'Abbé de La Chambre dans vostre pacquet, que je laisse ouvert, afin que vous y voiés une aventure qui m'est arrivée, dont je n'ai point voulu allonger davantage cette lettre». Quelques jours plus tard, le 14 avril 1680, dans une autre lettre toujours adressée au même destinataire, Galland précise: "Aujourd'huy je vous adresse la seconde lettre de mon voiage à Mr l'Abbé de la Chambre que j'ay eu le temps de mettre au net depuis que je vous ay écrit en arrivant. Vous aurés la bonté de l'envoier comme je ne doute point que vous aurés envoié la première. Car quoy que je n'en aie pas encore reçeu de nouvelle je ne laisse pas de me persuader que vous l'avés receue». V. M. Abdel-Halim, Correspondance, pp. 143 et 144.

${ }^{135} V$. par exemple ce qu'il devait dire à propos d'une relation d'Alexandrie (rédigée pendant le premier voyage d'Orient): «Je regrette beaucoup celle que je fis à Alexandrie, j'en perdis la minute au tremblement de terre et à l'incendie de Smyrne [en 1688, à la fin du troisième voyage], et la copie que j'avois envoyée à Mr Rainssant ne s'en est pas trouvée après sa mort». Lettre à P.-D. Huet, de Caen le 25 février 1701 éditée par M. AbdelHalim, Correspondance, p. 363.

${ }^{136} \mathrm{~V}$. par exemple Pitton de Tournefort, Relation d'un voyage du Levant fait par ordre $d u$ Roy, publiée à titre posthume en 1717, mais il était contemporain de Galland. À l'inverse, Chardin rédigera le récit de son voyage à partir de ses mémoires, après son retour en Occident. V. D. Van der Cruysse, op. cit., p. 215.

Nous possédons des informations se rapportant au premier voyage de Galland et à la méthode qu'il employait pour rédiger ses relations. «Je vous ay promis par ma dernière lettre une relation de nostre dernier voyage d'Andrinople, je m'acquitte de ma promesse. Vous y verrés un amas de quantité de choses mises en confusion, quoy que cette confusion ne soit pas sans ordre, puisqu'elle est dans celuy d'un Journal dont la beauté consiste en ce que les choses y soient traittées de la manière que je les traitte, c'est à dire comme elles se présentent et non pas avec choix comme dans une histoire bien suivie. Vous m'obligerés de me mander ce qui vous en aura semblé et aux amis auxquels vous l'aurés

Journal Asiatique 289.1 (2001): 1-66 
Sachant quels chemins la relation du Voyage fait en Levant suivit, il nous est permis de penser que la Smyrne ancienne et moderne, mais aussi le récit de son séjour à Messine, tous deux rédigés un an et demi à deux ans plus tôt, passèrent entre les mêmes mains. Peut-être furent-ils aussi expédiés à ses mécènes du moment, grâce auxquels il put faire ce voyage: Jean Foy-Vaillant et l'abbé Giraud (v. supra point C.1.a)? Toujours est-il que J. Spon était au fait des moindres détails du voyage puisqu'il déclare dans une lettre, datée de Lyon le $1^{\text {er }}$ décembre 1678 , et adressée à John Covel à Londres: «J'ay appris que vous aviez copié celle [l'inscription] de la porte du vieux chasteau de Smyrne, que je serois bien aise de voir ${ }^{137}{ }$. Spon fait ici référence au passage suivant de la Smyrne ancienne et moderne ( $\left.\mathrm{f}^{\circ} 43\right)$ : «[...] trois lignes d'une menue écriture grecque qui sont gravées sur le ceintre d'une porte que je n'ai pu lire pour ceste raison, et à cause qu'elle estoit trop élevée. Mais l'on m'a asseuré qu'elle est de l'Empereur Jean Ducas à ce qu'a rapporté Mons' Couvel, Ministre des Anglais, qui l'a transcrite aiant fait attacher à la muraille une certaine machine dont les matelots se servent pour calefater les vaisseaux».

\section{E. LE CHOIX DU TITRE DE LA SMYRNE ANCIENNE ET MODERNE}

En choisissant d'intituler sa relation de la ville de Smyrne Smyrne ancienne et moderne, Galland ne faisait que se conformer à une mode qui faisait florès à son époque. Il nous en fournit la raison dans le texte luimême (ff. 22ㄴ-23): «Mais considérant que l'on avoit desja donné au

communiquée, afin que je puisse me régler sur ce que j'auray à faire touchant le Journal de Smyrne». Lettre du 4 août 1673 adressée à Nicolas Petitpied. Galland envoya la relation du voyage d'Andrinople dans le même temps à un certain Baudequin. $V$. M. AbdelHalim, Correspondance, pp. 70 et 72.

Un peu plus tard, on trouve une justification de la rédaction des relations sous forme de lettres: «Vous serés bien aise d'estre adverti que je quitterai le stile ordinaire de mon Journal pour vous addresser toujours néantmoins suivant la daste des jours le voiage que nous allons faire en forme de lettres que je vous envoierai aux occasions qui se présenteront pendant le temps qui y sera emploié, afin d'éviter de vous en faire un trop gros pacquet pour vous l'envoier tout entier». Lettre à Nicolas Petitpied, le 12 septembre 1673. Ibid., pp. 97-8.

137 British Library, add. ms. 22910, ff. 180-1. Cette lettre fut transcrite par H. Omont dans ses Missions archéologiques, vol. II, pp. 1202-3. 
public l'estat de quelques villes grecques sous le titre d'ancienne et nouvelle, et que Smyrne avoit eu quelque éclat parmi celles de l'Asie Mineure dans l'Ionie qui en estoit une province très considérable et des plus florissantes, et qui devoit son origine aux colonies qui estoient presque toutes sorties de la ville d'Athènes, il m'a semblé que je ne devois rien dire de ce qu'elle est aujourd'hui, sans toucher quelque chose de ce qu'elle a estè autrefois». Mais le choix n'était pas si innocent qu'il y paraît. Nous savons que Galland avait pris part à la vive polémique qui opposa Jacob Spon à Guillet. Ce dernier avait publié en 1675 une Athènes ancienne et nouvelle et l'état présent de l'empire des Turcs, pour laquelle il s'était basé sur des géographes et historiens antiques grecs et les relations de pères capucins au Levant. Spon, qui accompagna dans son voyage en Orient l'anglais G. Wheler, put constater de visu que l'ouvrage de Guillet était rempli d'erreurs. Il se plut à les redresser, non sans l'aide de Galland qui se piqua au jeu, dans la relation de son voyage intitulée Voyage d'Italie, de Dalmatie, de Grèce et du Levant ${ }^{138}$. La polémique ne pouvait que s'envenimer et les deux auteurs se répondirent par l'intermédiaire d'ouvrages qui parurent coup sur coup. Guillet publia encore une Lacédémone ancienne et nouvelle, en 1676, et prévoyait une Delphe ancienne et nouvelle qui ne parut cependant jamais ${ }^{139}$. Au moment de choisir un titre pour la relation qu'il voulait donner de Smyrne, Galland, qui était encore tout empreint des suites de la polémique, prit la décision de s'inspirer de Guillet, peut-être en guise de clin d'oeil. Toutefois, à la différence de ce dernier, il opta pour le qualificatif «moderne». Tout ceci lui valut peut-être de ne finalement pas être publié par Barbin $^{140}$.

\section{G. Contenu de la SMyrne ancienne et moderne}

Bien que l'ouvrage porte un titre qui laisse supposer qu'il ne sera question que de Smyrne à l'époque ancienne et contemporaine, sous la forme d'une monographie, il apparaît en fait que le texte débute par la

${ }^{138}$ Lyon, 1678, 3 vol. in-12.

139 Sur la polémique et les références aux divers ouvrages, v. M. Abdel-Halim, Antoine Galland, p. 62 et suiv., ainsi que G. E. Reed, op. cit., p. 65.

${ }^{140}$ V. supra le point C.1. 
relation de son voyage de Messine à Smyrne, relation qui est rédigée à la manière d'un journal. Les dates sont précisées pour chaque escale, et figurent même assez souvent au début d'un paragraphe. Il se fait fort de relater le voyage décrivant au lecteur les événements qui émaillent chaque journée. Il ne laisse rien au hasard, qu'il s'agisse des vents dominants, des marées, des rencontres évitées avec les terribles corsaires.

Le récit de cette première partie débute le dimanche 20 février 1678 , date à laquelle Galland quitte Messine et s'embarque sur un navire. Le 23, il arrive à Augusta (Sicile), qu'il décrit avec beaucoup de précision. Le lendemain, il embarque sur un autre vaisseau commandé par un capitaine rencontré autrefois à Constantinople ${ }^{141}$; le 25, il entre dans l'Archipel, arrive au Cap de Sapience (Akra Tainaron) le 27 dans la soirée. Il ne parvient à Candie (Crète) que le mercredi 2 mars. Le lendemain, la crainte des corsaires se concrétise. On leur échappe de justesse. Il passe finalement le Cap de Saint-Jean (Akra Spatha) le 4, fait escale à Mykonos le 6 , après avoir croisé Milos. Il en profite pour descendre à terre et donne une brève description de l'île. Le vaisseau lève l'ancre le jour même et se retrouve le lendemain, 7 mars, à l'entrée du Golfe de Smyrne. Mais s'étant embourbé dans les célèbres bas-fonds du golfe, ce n'est qu'à l'aube du 8 qu'il entre dans la rade et vient jeter l'ancre devant la douane.

Soucieux de s'intégrer aux autochtones et de pratiquer les langues du pays, il déclare (ff. 21 ${ }^{\mathrm{v}}-22$ ): «Je songeai ensuite à un logement que je préférai de prendre dans un kan plus tost que dans une auberge, y en aiant plusieurs françoises, pour estre dans une plus grande liberté et pour estre aussi dans une pratique continuelle des deux langues les plus en usage dans le pais, c'est à dire de la turque et de la grecque. Je louai donc une chambre, assés grande et qui avoit veüe sur la mer, pour 40 sols le mois dans un <kan> qui estoit fort bien basti où il n'y avoit que des Grecs». Il dut, à son grand regret, quitter assez vite cet endroit au profit d'un logement dans une auberge, car ses compatriotes lui firent entendre qu'en cas d'épidémie de peste, ils ne pourraient rien pour lui. Son premier souhait est de prendre quelque repos et son souci majeur est

${ }^{141}$ Le capitaine Manère auquel les corsaires prirent un vaisseau le 11 mars $1673 . \mathrm{V}$. Ch. Schéfer, Journal d'Antoine Galland pendant son séjour à Constantinople, tome II, pp. 50-1. 
de ne pas passer son temps inutilement. C'est en ces termes qu'il explique pourquoi il décida de rédiger une histoire de Smyrne: «Après que je me fus ainsi establi, et que je crus que je pourrois doresnavant jouir de quelque repos, afin de ne pas passer inutilement le temps que j'avois à demeurer dans ceste ville, je pris la résolution de prendre toutes les informations qu'il me seroit possible de l'estat de ceste ville qui fait quelque bruit dans le monde à cause du commerce qui s'y fait (ff. 22-22v)». Ayant sans doute informé le Consul de France de son dessein, celui-ci lui montra un mémoire traitant de Smyrne, qui avait été rédigé l'année précédente. Son principal souci est alors de le vérifier dans le moindre détail et d'y adjoindre ses observations personnelles glanées au cours de ses nombreuses promenades dans la ville et ses environs, ainsi qu'au fil de ses conversations avec les autochtones.

C'est à cet endroit qu'il exprime son intention de d'abord rapporter l'histoire de cette ville depuis sa fondation jusqu'à sa conquête par les Turcs, en se basant sur les auteurs antiques; ceci constitue le premier volet de la seconde partie de la Smyrne ancienne et moderne. Les sources dont il dispose sur place sont Pausanias, Strabon, Stéphanus. Il y ajoutera, de retour à Paris, Aristide. Toute cette partie paraîtrait moins originale, si Galland n'y ajoutait ses commentaires personnels concernant notamment des inscriptions grecques lues à même les monuments préservés, qu'il retrouve parfois chez quelque marchand turc particulièrement riche. "Il y avoit quelque temps, nous dit-il à son propos (ff. 38-38v), qu'il en avoit enlevé un [un tombeau de marbre], qu'il a fait apporter dans la ville, où il le conserve dans un kan, et en a desja refusé d'un marchand anglois deux pièces de londrine qui valoient près de deux cents écus. Je l'ay veu dans cet endroit, par un costé seulement, parce qu'il l'a couvert de pierres pour empecher les Turcs indiscrets et trop superstitieux de gaster la sculpture qui le rend considérable. Ce sont des génies, des feuillages, des limaçons, des oiseaux, des serpens, des masques et autres galanteries qui sont d'un très beau dessein». Car, outre le commerce, ce qui intéresse les Occidentaux dans ces contrées éloignées, ce sont les antiquités, grecques ou romaines, aussi bien que les manuscrits: statues, médailles et monnaies ou inscriptions que les Consuls de chaque nation ou des marchands intéressés tentent d'acquérir, parfois à prix d'or. Galland ne faisait pas exception: il fut envoyé deux fois en Orient dans ce but. 
Après avoir décrit la Smyrne ancienne, il envisage d'en donner une description telle qu'elle est à son époque, sous l'empire des Turcs, en se basant, à nouveau, sur des mémoires «qui m'ont esté communiqués et que j'ai vérifiés sur les lieux». "On y verra, avoue-t-il (f. 45v), dans le gouvernement et dans la police des Turcs un modèle de ce qui se pratique dans toutes les autres villes de leur Empire, et je ne doute pas que les personnes intelligentes n'en tirent plusieurs conclusions pour destruire la préoccupation qu'ils peuvent avoir de la grandeur et de la puissance de l'ennemi commun de la chrétienté». Il commence par dépeindre la position de la ville moderne, son plan, le nombre de quartiers et de maisons, les principaux monuments qui la composent: le bezistān tout neuf, les hāan-s, etc. De la douane, il nous dit (ff. 48-48v): «C'est un bastiment nouveau, qui n'est que de bois et basty sur pilotis, avec une grande avance de planches soutenüe en l'air sous laquelle la mer bat, avec des degrés pour monter et pour descendre à la mer, et pour décharger les bales de marchandises. Les marchands sont beaucoup mortifiés de ceste nouveauté, parce qu'on les oblige d'y faire aborder ce qu'ils veulent débarquer ou embarquer pour estre fouillé et examiné, afin que les droits ne soient point frustrés et pour empescher les marchandises de contrebande, qui estoient auparavant fort fréquentes lorsque chacun débarquoit directement à son magazin, ou qu'il embarquoit pour envoier aux vaisseaux. On dit que les Consuls n'en sont point faschés parce que les marchands ne peuvent rien soustraire à leurs droits en faisant embarquer quoi que ce soit à son insceu, pouvant avoir connoissance de tout par le mémoire de la doane».

Il dénombre et décrit ensuite les mosquées à propos desquelles il se livre à l'étymologie (ff. 51-51 ${ }^{v}$ ): «Les dix huict premières mosquées s'appellent proprement Dgiami, c'est à dire lieu d'assemblée, à cause de leur grandeur et de leur capacité, mais il y en a soixante autres qu'on appelle simplement Mesgides, c'est à dire lieu d'adoration ${ }^{142}$, qui n'ont point de minarets, elles sont pour la commodité de ceux qui demeurent aux environs et pour les soulager de la fatigue d'aller aux plus grandes, particulièrement le matin et le soir, qu'il faut prier une demie heure de-

${ }^{142}$ La définition que donne ici Galland correspond plus au mot ma'bad. Le mot masğid désigne en fait un lieu de prosternation (du verbe arabe sağada, se prosterner). 
vant le jour, et une heure et demie après que le soleil est couché. Ce mot de Mesgid a donné lieu au nostre de mosquée que nous avons pris des Italiens qui ont plustost eu commerce avec les Turcs que nous, et qui de là ont dit, Meschita ${ }^{143}$, Moschetta et Mosquea».

La description géographie et topographique terminée, Galland s'attache à dépeindre la population de cette ville cosmopolite. Son point de départ est les Francs, «nom que l'on donne aux chrestiens qui viennent d'Europe dans les terres du Grand Seigneur. [...] Ils sont ou François, ou Anglois, ou Hollandois, ou Vénitiens, ou Génois desquels je parlerai les uns après les autres (ff. 53 ${ }^{-54}$ )».

À tout seigneur, tout honneur, il traite avant tout des Français, mais c'est sa description des autres nations européennes qui ne manque pas de piquant et, parfois, de perspicacité. À propos des Anglais, il affirme (ff. $\left.57^{\mathrm{v}}-58^{\mathrm{v}}\right)$ : «Ils disent presque tous qu'ils sont gentilshommes, mais il y en a beaucoup qui ne sont point de meilleur maison que les nostres. Ils boivent presque autant de vin que toutes les autres nations ensemble. L'altération que les excès qu'ils en font causent à leur santé les met fort peu en peine. Ils préfèrent le plaisir de boire à toutes les incommodités qui peuvent leur arriver, et de tous ceux qui meurent à Smyrne, il y en a peu dont on ne puisse asseurer avec vérité qu'ils sont morts pour avoir trop beu; et l'on en peut tirer un argument de ce que l'on remarque aux épitaphes de leur cemetière dans lesquels ils ont soin de publier leur aage, que l'on trouve estre presque à tous au-dessous de quarante ans». Ou encore, décrivant les Hollandais ( $f^{\circ}$ 60): «Ils sont tous civils et honnestes, et ils ont plus d'inclination envers nostre nation que les Anglois qui ne peuvent abandonner leur fierté naturelle, non pas mesme en changeant de pais et en voiageant, quoique ce soit un moien qui civilise ordinairement les esprits les plus grossiers et l'on peut dire d'eux avec vérité que cœlum non animum mutant ${ }^{144} \gg$. Les relations tendues entre le roi d'Angleterre et le roi de France semblent déteindre sur notre voyageur. Mais il faut bien reconnaître que l'attitude des Anglais envers

${ }^{143}$ Le Dictionnaire historique de la langue française (s. v. mosquée) précise que cette forme est attestée en espagnol (mezquita), et non pas en italien.

${ }^{144}$ Horace, Épîtres, livre I, épître XI, v. 27 (cœelum, non animum mutant qui trans mare currunt, littéralement «Ceux qui courent au-delà des mers changent de ciel, pas d'âme»). 
les Français, surtout dans les milieux populaires des marins, n'a pas contribué à un adoucissement de son opinion à leur égard. Ainsi frisa-t-on, durant son séjour même, le 7 avril, l'incident diplomatique après qu'un marin anglais, ivre de surcroît, eut traité certains Français de chiens. Le tout dégénéra en bagarre, et plusieurs Anglais parvinrent même à pénétrer dans le consulat de France. Ce ne fut que grâce à l'intervention du consul d'Angleterre, et après avoir menacé ses compatriotes de la loi martiale, qu'ils acceptèrent de se retirer. Les ambassadeurs respectifs en poste à Constantinople donnèrent ordre à leur consul à Smyrne de tout faire pour préserver des relations cordiales entre les deux nations, et ce même si une guerre devait éclater entre elles en Europe. Le pérennité du commerce prévalait avant tout ${ }^{145}$.

Galland s'intéresse tout particulièrement au statut de ces chrétiens vivant en «terre infidèle», soulignant que leurs démêlés ne regardent en rien la justice turque pourvu qu'aucun ressortissant de la Porte n'y soit impliqué. Quant aux relations qu'ils peuvent avoir avec des musulmanes, «c'est parmi eux un sacrilège d'en approcher qu'il faut paier par le feu ou par l'abjuration du christianisme ou par une grande profusion d'argent, encor faut-il qu'elle se fasse presque aussitost que l'on est surpris, car il n'y a plus rien à faire lorsque la justice en a pris connoissance (ff. 65-65 ${ }^{\mathrm{v}}$ )». Et notre savant, assez prude, de conclure (ff 65-66): «Néantmoins, il seroit à souhaiter que la rigueur y fust toute entière connue dans les eschelles des costes de Syrie et d'Égypte, non seulement pour l'avantage des asmes et pour cacher le scandale que nostre religion en souffre parmi ces infidels, mais aussi pour conserver les bourses des marchans qui dépensent dans leurs débauches ce qui pourroit leur servir à faire un plus grand gain».

Ayant terminé la description des différentes nations européennes vivant à Smyrne, Galland s'intéresse aux autres habitants de la ville: les rayas. D'abord, les Arméniens et les Grecs, pour qui «ce leur est une mortification des plus sensibles d'estre obligés de vivre ensemble sans

145 Outre le compte rendu de Galland, on possède une version anglaise de l'échauffourée. Elle est contenue dans une lettre signée de l'ambassadeur anglais à Constantinople, Sir John Finch, et adressée à Coventry le 14/24 mai 1678 (le calendrier protestant ne tenait pas encore compte de la modification introduite par le nouveau calendrier grégorien). V. S. Anderson, An English Consul in Smyrna, p. 250. 
$s^{\prime}$ en rien tesmoigner les uns aux autres» ( $\left.\mathrm{f}^{\circ} 71\right)$; puis les Juifs, pour lesquels il souligne l'obligation de suivre les lois ancestrales établies par leurs pères, coûte que coûte, rapportant à ce sujet une plaisante anecdote (ff. 75-76): «Néantmoins, lorsque quelqu'un se rebelle et ne veut pas reconnoistre la jurisdiction de leur tribunal, ils sçavent se vanger tost ou tard du mépris qu'ils en font. Il y a quelques années qu'ils avoient desfendu à un Juif, que je connois, qui est italien, et qui parle très bien nostre langue [...], de porter le chapeau, et ordonné de prendre leur bonnet. Mais le trouvant trop ridicule pour s'y accommoder, il fit la sourde oreille, et ne se soucia point de leur obéir. Mais un jour, il fust extrêmement surpris de se voir arresté par ordre de la justice des Turcs et mené au cadis devant lequel deux Juifs vinrent lui maintenir qu'il devoit trente écus. Il eust beau protester le contraire, il fust condamné de paier. Néantmoins, cela n'a pas empêché qu'il n'ait tousjours porté le chapeau et qu'il ne le porte encor, s'estant mis sous la protection des Anglois qui luy ont donné de l'emploi dans leur chancelerie». Il met aussi l'accent sur leur aptitude commerciale (ff. 78-78v): «Ceux-ci font quelquefois de bons coups lorsqu'ils ont affaire à des nouveaux venus qui ne sçavent point l'usage du pais. Leur conscience n'est pas beaucoup inquiétée des tromperies qu'ils font pour attraper leur argent, croiant que ce n'est pas un crime pour eux de faire tort à ceux qui ne sont pas de leur loi. Mais la crainte qu'ils ont d'estre surpris et punis, fait qu'ils le font autant qu'ils peuvent con bel modo, c'est-à-dire si adroitement que l'on ne puisse pas s'en appercevoir, ou si l'on s'en apperçoit qu'on n'ait pas lieu de s'en fâcher».

Galland étudie avec une grande minutie les aliments disponibles à Smyrne, traitant du blé, de la viande, du vin, du café et de l'eau-de-vie, en remarquant au passage que «au regard du vin, on sçait que les Turcs n'en boivent pas, ou du moins s'ils en boivent, comme il y en a plusieurs qui le font, ils n'en font point de provision, mais le prennent chez les chrestiens» ( $\mathrm{f}^{\circ} 82$ ). Il pousse même le souci du détail jusqu'à donner une liste complète des marchandises qui s'achètent à Smyrne pour l'exportation (65 produits) et celles importées de Chrétienté qui s'y vendent (40 produits), classées selon l'unité de débit (battaman, quintal, ocque, pic, chequis ou à la pièce). Cette section sur le commerce ne pouvait se clôturer sans une description des monnaies qui ont cours sur les marchés 
de Smyrne et de la langue employée par toutes ces nations. Il remarque à ce propos que «puisque toutes ces nations qui sont si différentes les unes d'avec les autres de mours, de religion, de rit et de façon de faire, ont commerce ensemble, et que leur langage ne se ressemble pas, quelque curieux pourroit demander comment elles se font entendre lorsqu'elles ont à traitter l'une avec l'autre» ( $\mathrm{f}^{\circ} 84$ ). C'est l'italien qui l'emporte sur les autres langues, mais un italien quelque peu corrompu dont il donne un exemple: «Hau ven aqui, ti voler per questo, per Dio mi far bon mercato, star bona roba, pigliar perti, c'est-à-dire «Vien ça! Veux-tu achepter cela, je t'en ferai bon marché, la marchandise est bonne, prens-la». Le fréquent usage de ce jargon et de la langue italienne fait que les marchands s'appliquent peu à apprendre ni la turque, ni la grecque, si ce n'est quelquefois celle-ci dont il y en a qui apprennent quelque chose par la conversation qu'ils ont avec les femmes. Sur quoi j'ai fait un reproche à nos marchands de leur négligence puisque dans les eschelles d'Égypte et de Syrie, ils apprennent l'arabe qui est une langue bien plus difficile, et ils m'ont respondu que tout le monde parlant arabe dans ces lieux-là, jusqu'aux Juifs desquels ils ne peuvent se passer, ce leur est une nécessité de l'apprendre. Mais qu'ils ont ici si peu de fréquentation avec les Turcs qu'ils ne se soucient pas d'estudier leur langue» ( $\left.\mathrm{f}^{\circ} 85\right)$.

Ce que l'on reprochait à la plupart des récits de voyages de l'époque de Galland, c'était le manque d'intérêt de leurs auteurs pour les populations. La principale cause résidait dans le fait que ces voyageurs parlaient rarement la langue du pays, se faisant aider par quelque interprète à la merci duquel ils étaient. Galland ne rencontre pas ce genre de problème: il se débrouille très bien dans plusieurs langues orientales. De là, son souci de décrire avec le plus d'exactitude les principaux personnages de la ville de Smyrne: le muftī, le cadi, le pacha, le vaivode, le serdār, le kāhya ğeri et le douanier. Son compte rendu est d'une grande précision pour l'époque, comparé aux informations disponibles en ce temps-là ${ }^{146}$.

146 Il appliquait en cela un conseil fort judicieux: «J'ai beaucoup profité pour ce travail d'une instruction que Mr Justel m'avoit donnée: particulièrement de ne rien dire de ce qui auroit été mentionné par les autres voyageurs, de corriger leurs fautes et de particulariser ce qu'ils avoient négligé». Lettre adressée à Huet, de Caen, le 25 février 1701 et transcrite par M. Abdel-Halim, Correspondance, p. 363. 
Nous soulignerons particulièrement cette information rapportée à propos de l'office de vaivode (ff. 98-99): «Mais un des beaux droits qu'il ait est sur ceux qui se trouvent en débauche avec les femmes, parce que l'amende n'est pas limitée et qu'il peut exiger le plus qu'il peut suivant les richesses de ceux qu'il surprend. Mais il y en a plusieurs, et particulièrement des Francs, qui lui donnent qui dix, qui vingt écus par an pour avoir un billet de lui qui leur donne la liberté de fréquenter celles qu'ils veulent, et pour se mettre à couvert de l'affront d'estre mené en prison ou de recevoir quelque autre mauvais traittement. Néantmoins, afin que le Cadi ne trouve rien à redire à une telle permission qu'il pourroit trouver de mauvais exemple et contraire aux loix, il met simplement qu'il donne la permission à un tel Franc d'aller à la maison ou au jardin d'une telle pour faire blanchir son linge. Cela ne les met pas beaucoup plus en seureté, parce que comme ils sont connus et que l'on sçait les lieux qu'ils fréquentent, il ne manque pas de les importuner souvent et de leur en faire débourser davantage. Il y a des filles qui obtiennent aussi de ces billets afin d'estre visitées par les Francs avec liberté, et l'on en a desjà veu qui par ce moien sont arrivées à en épouser de bien riches, quoiqu'elles n'eussent aucun bien».

Ce tableau social dressé, il ne restait plus à Galland qu'à énumérer les impôts prélevés pour diverses raisons, les maladies qui frappent les habitants de la ville (peste, petite vérole), les ressources agricoles de la ville et les principaux villages qui l'environnent. Il s'évertue ensuite à démontrer que la puissance turque n'est en grande partie qu'artifice, prenant en exemple la ville de Smyrne qu'il dit mal fortifiée et qui ne résisterait pas bien longtemps à un assaut chrétien. Cette opinion était dans l'air depuis quelque temps ${ }^{147}$. Mais les fortifications ne sont pas seules

147 Un projet de conquête de l'Égypte avait déjà germé dans l'esprit de Leibniz, qui en avait fait part à Louis XIV, lors de son séjour à Paris en 1672. Si ce projet ne connut pas de suite, on sait par contre que le Roi-Soleil fut tenté par une conquête de Constantinople qui aurait dû lui ouvrir les portes de l'Orient et lui assurer la renaissance d'un Empire auquel les Ottomans avaient mis fin par la prise de la même ville. Cette idée lui vint en 1685 , peu après l'échec de la prise de Vienne. Afin de donner le maximum de succès à l'entreprise, on fit procéder à un relevé minutieux et descriptif de toutes les forteresses des principales échelles levantines par un capitaine de vaisseau du nom de Gravier d'Ortières, qui était accompagné de plusieurs ingénieurs de la marine. Le compte rendu de cette enquête figure dans un Mémoire touchant les Echelles du Levant et un Estat des places que les princes mahométans possèdent sur les costes de la mer Méditerranée et 
en cause: les hommes qui pourraient s'opposer à un tel assaut seraient, toujours selon lui, bien peu nombreux. Il remarque ainsi que «les Turcs ne sont pas aussi en grand nombre, et bien loin d'augmenter, on remarque qu'ils vont tousjours en diminuant, non seulement parce que de temps en temps la peste en destruit une partie, mais à cause aussi qu'ils ne peuvent pas avoir d'enfans. Plusieurs forment de grands raisonnemens sur leur stérilité, ne sçachant pas bien sur qui en rejetter la faute, ou sur les hommes ou sur les femmes. A l'égard des femmes, il y a un grand sujet de douter si le grand usage du bain, et particulièrement après avoir eu affaire avec leur mari, afin de se purger de l'immondicité qu'elles croient avoir contractée, ne contribüe pas à rendre la semence inféconde par une trop grande dissipation des esprits causée par la relaxation de toutes les parties du corps. Pour les hommes, ont leur reproche la communication avec les garçons qu'ils préfèrent à celle des femmes. D'autres veulent que la pluralité des femmes soit contraire à la génération, et quelques-uns m'ont asseuré qu'il y a en avoit beaucoup qui fuioient leurs femmes, parce qu'ils ne pouvoient pas supporter la mauvaise odeur qui exhale de leur corps, soit qu'elle procède des méchantes nourritures qu'elles prennent, ou plustost de ce qu'elles vont trop souvent au bain» (ff. 116 1117 ).

On ne s'étonnera pas de voir Galland conclure ce second volet de la deuxième partie de son ouvrage en ces termes: «Je ne veux point porter ces réflexions plus loing, mais je laisse à considérer aux personnes intelligentes qu'il n'y a que faiblesse dans tous les estats du Gr. Seigneur: peu de monde et peu d'argent, et que si les princes chrestiens rompoient le commerce qu'ils y ont, ce seroit un grand acheminement pour les ruiner entièrement. Car il faut considérer que n'aiant ni mine d'or, ni mine d'argent, il n'y a que le commerce, que les chrestiens font pour la plus grande part, qui puissent leur en apporter ( $\left.\mathrm{f}^{\circ} 117^{\mathrm{v}}\right) »$.

dont les plans ont esté levez par ordre du Roi à la faveur de la visite des Eschelles de Levant, que Sa Majesté a fait faire les années 1685, 1686 et 1687, avec les projets pour y faire descente et s'en rendre maistres, tous deux de la main de Gravier d'Ortières et conservés à la BnF. À ce sujet, $v$. H. Omont, Projets de prise de Constantinople et de fondation d'un empire français d'Orient sous Louis XIV, dans Revue d'histoire diplomatique 7 (1893), pp. 195-246.

On constate cependant que déjà en 1678, Galland faisait état de la faiblesse de l'Empire ottoman, répondant en cela à un état d'esprit qui prévalait en Occident. 
C'est avec ces propos négatifs, et quelque peu prémonitoires, que notre voyageur aurait pu mettre un point final à sa description de Smyrne. Il décida toutefois d'ajouter une troisième partie, qui vient renforcer le caractère exceptionnel de ce texte qui avait commencé comme une relation de voyage, s'était transformé en traité historique et archéologique pour l'état antique de la ville, puis en étude sociologique et ethnographique pour l'époque contemporaine. Voici en quels termes il l'annonce: «Auparavant de finir ce discours, je veux vous entretenir des mours des Turcs en général à l'occasion de ceux de Smyrne. C'est une matière que tous les voiageurs et tous ceux qui ont écrit de la Turquie ont traitté à leur manière. Mais j'espère que celle dont je me sers ne vous déplaira pas. Vous verrès les mours et les façons de faire de cette nation opposées aux nostres, article par article, et vous serès estonnès comment les hommes peuvent avoir si peu de ressemblance les uns aux autres ( $\left.\mathrm{f}^{\circ} 118\right) »$.

Afin de souligner ce qui fait la spécificité des Turcs par rapport aux Européens, et plus particulièrement aux Français («estant plus certain de ce qui se pratique en France que dans les autres pais»), Galland s'attache, dans les 166 articles qui suivent et sous forme d'aphorismes, à relever des antagonismes essentiellement relatifs aux coutumes et au culte des uns et des autres, se livrant ainsi à une véritable enquête d'anthropologie culturelle comparée avant la lettre. Le principe était pourtant connu depuis la Renaissance, et plusieurs exemples en sont connus. L'un des plus célèbres est désormais l'ouvrage traitant des Japonais du père jésuite portugais Luís Fróis (m. en 1585), qui contient plusieurs centaines d'antithèses et était resté à l'état de manuscrit avant d'être finalement édité au XX $\mathrm{XX}^{\mathrm{e}}$ siècle $^{148}$. Quant à Galland, il avoue avoir été inspiré dans sa façon de faire par l'ouvrage d'un autre père jésuite, dont il nous tait à la fois le titre et le nom de l'auteur, se contentant de nous dire qu'il y était question des contradictions de mœurs entre les Arabes de Syrie et les Français ${ }^{149}$. Notre tâche pour l'identification de cette source aurait été

148 Tratado em que se contem muito susinta e abreviadamente algumas contradições \& diferenças de custumes antre a gente de Europa \& esta provincia de Japão. Édité et traduit en allemand par J. F. Schütte en 1955. Traduit en français par Xavier de Castro et Robert Schrimpf, Paris (Chandeigne), 1993, s. 1. t. Traité de Luís Fróis, S. J. (1585) sur les contradictions de mœurs entre les Européens et les Japonais.

149 «Je scai bien que j’ay estè prévenu sur ce sujet par un père jésuite, mais comme il 
plus ardue qu'elle ne le fut si, dans une note insérée dans son Journal des années 1708-1715, il n'y avait fait explicitement référence: «Vendredi 13 de juin 1710: J'achetai, pour en faire plaisir à quelque curieux de relations de voyages, la Syrie sainte $d u$ P. Besson, jésuite, missionnaire à Alep, où je l'avais vu [en] $1704^{150}$. Ce qu'il y a de plus particulier, c'est ce qu'on trouve à la fin, p. 250, touchant l'antipathie de la Syrie et de l'Europe, et l'opposition de la France et de la Syrie pour les habits et pour les coutumes ${ }^{151} »$. Le père Joseph Besson (Carpentras, 1610-Alep, 1691) fut supérieur des missions de Syrie et est l'auteur de La Syrie sainte ou la Mission de Iesus et des Pères de la Compagnie de Iesus en Syrie ${ }^{152}$. Dans la seconde partie (traité III, remarque IV) se trouve un chapitre (II) couvrant les pp. 250-69 et intitulé L'Antipathie de la Syrie et de l'Europe. Besson s'en justifie de la manière suivante: «Ces peuples sont les antipodes de l'Europe, et nommément de la France, aux habits, au manger, aux coutumes, en la conversation, aux sciences et aux cérémonies: ainsi ce chapitre sera composé d'antithèses qui rendront la narration agréable, et seront une peinture achevée de cette province. Il y a, ce me semble, une liaison bien étroite, entre la France et la Syrie, qui en a reçu de si puissants secours aux siècles d'or des Croisades; mais d'ailleurs il y a une très grande opposition en tous les chefs que nous avons touchés, et que nous expliquerons plus au long».

Les antagonismes, guère plus nombreux que ceux qui figurent à la fin de la Smyrne ancienne et moderne, se suivent selon un classement par

n'a presque parlè en particulier que des mœurs des Arabes qui sont dans la Syrie, il y a bien des choses dans lesquelles nous ne nous rencontrons pas; et de plus, son livre estant devenu rare, par le soin que ceux de sa compagnie mesme ont pris de le supprimer, vous serés bien aise de trouver icy ce que je dis de commun avec luy» (ff 118-118v).

150 Sic! Lisez 1674, année où Galland accompagnait le marquis de Nointel, ambassadeur de France à Constantinople, dans son voyage dans les échelles levantines destiné à annoncer aux ressortissants français le renouvellement des capitulations qu'il avait obtenu de la Porte.

${ }^{151}$ H. Omont, Journal parisien, p. 78.

152 Divisée en deux parties. Paris: Jean Henault, 1660. L'ouvrage parut à Rome deux ans plus tard, dans une version italienne due à J. Anturini. Il resta dans l'oubli avant d'être réimprimé au XIX ${ }^{\mathrm{e}}$ siècle; ce qui vient corroborer les propos de Galland au sujet de sa rareté au $\mathrm{XVII}^{\mathrm{e}}$ siècle déjà par cause de sa mise à l'index par ses frères en religion. $V$. C. Sommervogel, Bibliothèque de la Compagnie de Jésus, tome I, col. 1412. 
matières: l'opposition de la France et de la Syrie pour les habits (p. 250), du manger (p. 254), quelques autres coutumes (p. 256), la conversation (p. 261), les livres et les sciences (p. 263), les cérémonies (p. 265). Pour sa part, Galland s'inspira de ces rubriques, en les développant, mais il s'abstint de donner des titres. Ainsi découvre-t-on, à la lecture de ces antithèses, qu'il aborde la question de l'habillement, des pratiques alimentaires, des femmes, de la literie, de l'équitation, des pratiques cultuelles, de l'enseignement, des chiens, des jardins, des voyages, des pratiques de la vie quotidienne, du calendrier, des pratiques mortuaires, de la justice, du souverain, de la médecine, de la musique, de la maison, de l'armée. Enfin, les derniers articles, que l'on pourrait qualifier de divers, indiquent que notre auteur ajouta des différences qui lui vinrent à l'esprit a posteriori, car elles ressortissent à des catégories déjà traitées, mais n'y ont pas été insérées au moment opportun, sans doute parce que la copie de l'ouvrage était déjà terminée.

La comparaison d'un aphorisme figurant dans La Syrie sainte de Besson avec l'un de ceux qui apparaissent dans la Smyrne ancienne et moderne, au sujet de l'habillement, fait mieux ressortir à quel point la liste du premier servit de source d'inspiration à Galland:

La Syrie sainte (p. 250)

«En France, l'habit n'est pas complet, s'il n'est tout de même étoffe et d'une même couleur; ici l'habit n'est pas agréable s'il n'est bigarré de diverses couleurs»
Smyrne ancienne et moderne ( $\left.\mathrm{f}^{\circ} 121\right)$

«On s'habille en France d'une manière que tout se trouve assortissant à une même couleur. Mais les Turcs se plaisent à estre bigarrés de plusieurs toute à la fois. Tel aura le bonnet de son turban verd, le saric ${ }^{153}$, qui est la toile dont il est environné, blanc, le doliman gris de lin, la veste bleüe, le chakchir ${ }^{154}$, ou haut de chausses, rouge et les papouches jaunes»

La comparaison s'arrête là car, à la différence de Besson, Galland ne se contente pas de relever les contradictions neutres ou en défaveur des Turcs. Bien au contraire, soucieux semble-t-il d'impartialité, ce qui l'honore, il relève, parfois sarcastiquement, telle pratique turque dont les

${ }^{153}$ Lisez sarlk.

${ }^{154}$ Lisez çakşır. 
Français tireraient tout avantage en l'imitant: «Les Turcs ont un grand soin d'avoir leur corps net en entrant dans les mosquées; et ce seroit le devoir des François, comme bons chrestiens, d'avoir tousjours l'âme nette lorsqu'ils entrent dans les églises $\left(\mathrm{f}^{\circ} 128^{\mathrm{v}}\right)$ ». Le regard particulièrement acerbe qu'il pose sur la civilisation ottomane vaut tout autant pour ses compatriotes ainsi qu'il le démontre en parlant de certaines femmes françaises: "Plusieurs femmes en Turquie se contentent d'un mari; il y en a en France qui, quoiqu'elles soient mariées, veulent avoir encor des galants ( $\left.\mathrm{f}^{\circ} 125^{\vee}\right) »$, la critique tournant parfois à l'autodérision, comme il le prouve en décrivant la soldatesque: «Il ne faut qu'une tente de vingt ou vingt-cinq pieds de diamètre pour loger cinquante janissaires; il n'en faudroit pas moins pour quatre François seulement. Il n'est point rare de voir dix mille janissaires dans un silence admirable; mais il faudroit avoir une grande authorité pour l'imposer à dix soldats françois (ff. 136-136 ${ }^{v}$ )».

On le constate: il fallait à Galland une acuité hors norme pour être à même de relever autant de différences pertinentes entre Français et Turcs. Cette acuité implique une connaissance intime tant de sa propre culture que de celle de l'Autre, connaissance qui se trouve renforcée par une longue fréquentation des autochtones, elle-même facilitée par la pratique de plusieurs langues orientales.

\section{H. IMPORTANCE POUR L'EeUVRE DE GALLAND}

Le caractère fondamental du manuscrit bruxellois pour une meilleure connaissance de la vie d'Antoine Galland apparaît trop manifeste pour faire l'objet d'une étude détaillée: il nous offre enfin la possibilité de jeter une lumière sur une période de sa vie qui, jusqu'à maintenant, était des plus obscures. Ce bref intervalle de presque un an, dont on ignorait tout, se voit désormais raccourci aux quelques mois passés à Messine, dont la relation nous manque toujours cruellement.

Quant à son apport pour une connaissance approfondie de l'œuvre du traducteur des Mille et une nuits, il vaut la peine d'être souligné ici. En effet, l'auteur de la Smyrne ancienne et moderne nous fournit de précieux indices pour corroborer et attester l'existence de certains textes qui lui sont attribués de longue date, ou que l'on ignorait totalement. 
C'est ainsi que nous savons désormais que la relation de Messine, qu'il évoquait encore dans sa correspondance en $1701^{155}$, est relative au séjour qu'il fit dans cette ville, entre fin 1677 jusque mi-février 1678, à l'occasion de son second périple en Orient. Bien plus, nous sommes enfin sûrs que ses destinataires étaient ceux de la Smyrne ancienne et moderne.

Le texte nous fournit encore une donnée importante s'agissant d'un autre écrit de Galland. Décrivant les fonctions du muftī, il déclare ( ${ }^{\circ} 52$ ): "[...] il a encor l'avantage de donner des décisions sur les questions de droit qui sont controversées, au sujet desquelles il est consulté, et elles ont un tel poids qu'elles sont presque tousjours suivies par les cadis. C'est ce que l'on nomme fetfa, dont j'ay desjà parlé et donné des exemples dans un autre escrit». Nul doute qu'il fait ici référence à une Relation touchant la manière d'administrer la justice parmy les Turcs, destinée à Nicolas Petitpied et expédiée au même le 17 avril 1673. L'existence de ce texte, toujours considéré comme perdu, était seulement attestée par une mention dans le brouillon de la lettre qui accompagnait ladite relation ${ }^{156}$.

Galland s'est révélé être un infatigable traducteur de textes arabes, persans et turcs. On lui connaissait aussi des traductions à partir du grec. Toutefois, on ignorait jusqu'à ce jour qu'il avait entrepris, dès le début de ce second voyage en Orient, une traduction de l'ouvrage d'Étienne de Byzance intitulé Perì póleōn. Il prit la peine d'en parler (ff. ${ }^{\circ} 61-61^{v}$ ) pour simplement annoncer qu'il avait renoncé à ce travail depuis qu'il avait appris, par l'intermédiaire d'un marchand hollandais amoureux des belles-lettres, qu'un savant professeur de Leiden travaillait à son impres$\operatorname{sion}^{157}$, et bien plus encore qu'un autre personnage, du pseudonyme de Pinède, en avait préparé une autre édition qui devait être sous presse ${ }^{158}$.

$155 V$. note 30 .

156 V. M. Abdel-Halim, Correspondance, p. 34.

157 Il s'agit de l'édition d'Abraham Berkelius parue sous le titre Genuina Stephani Byzantini de urbibus et populis fragmenta, Lugduni in Batavis, apud D. A. Gaesbeeck, 1674. Il publiera, en 1688, une édition complète s. 1. t. Ethnikà kat' epitomen Stephani Byzantini Gentilia per epitomen, antehac Perì póleōn, de urbibus, inscripta, Lugduni Batavorum, apud D. A. Gaesbeeck.

${ }^{158}$ L'édition en question parut sous le titre suivant: Perì póleōn. Stephanus de Urbibus quem primus Thomas de Pinedo lusitanus: latii jure donabat, et observationibus Scrutinio Variarum Linguarum, ac pracipue Hebraica, Phoenicia, Graca et Latina detectis illustrabat, his addita prater ejusdem Stephani Fragmentum Collationes Jacobi 
Tels sont les éléments essentiels que Galland nous a transmis dans sa relation de voyage et qui nous permettent de compléter son curriculum vitae.

\section{BIBLIOGRAPHIE}

a) Manuscrits

BABIN J.-P., Relation de l'Isle de Tines. Bruxelles, Bibliothèque Royale Albert Ier, ms. II 5359, ff. 185-196.

Enregistrements des privilèges commençant au $23^{e}$ octobre 1673. Paris, BnF, ms. fonds fr., n ${ }^{\circ} 21946$.

Galland A., Smyrne ancienne et moderne. Bruxelles, Bibliothèque Royale Albert Ier, ms. II 5359, ff. 3-137.

_- Sommaire ou Mémoire chronologique de la vie d'Antoine Galland. Paris, BnF, ms. fonds fr. n. a., $\mathrm{n}^{\circ} 11403$.

_- Voyage fait en Levant. Munich, Bayerische Staatsbibliothek, cod. gall. 727-728.

Georgerine J., Estat présent des Isles de Samos, Nicarie, Patmos et du Mont Athos. Traduction d'Antoine Galland. Bruxelles, Bibliothèque Royale Albert Ier, ms. II 5359, ff. 138-183 . Munich, Bayerische Staatsbibliothek, cod. gall. 751 .

b) Imprimés.

Abdel-Halim M., Antoine Galland, sa vie et son æuvre. Paris: Nizet, 1964, 547 p.

— Correspondance d'Antoine Galland. Édition critique et commentée. Thèse complémentaire pour le Doctorat ès-lettres, présentée à la Faculté des Lettres et Sciences humaines de l'Université de Paris, 1964, 692 p.

Anderson S., An English Consul in Smyrna. Paul Rycaut at Smyrna, 16671678. Oxford: Clarendon Press, 1989, XII-323 p.

Besson J., La Syrie sainte ou la Mission de Iesus et des Pères de la Compagnie de Iesus en Syrie. Divisée en deux parties. Paris: Jean Henault, 1660.

Biographie universelle. Tomes VI (1811), X (1813), XVI (1816). Paris: chez Michaud Frères.

Biographie universelle, ancienne et moderne. Supplément. Tome LXX. ParisWiesbaden, 1842.

Gronovii cum codice Perusino, una cumgemino rerum et verborum indice ad Stephanum et Thoma de Pinedo observationes, Amstelodami, typis J. de Jonge, 1678. 
BRotier, Mémoire sur le tableau de Ialysus, peint par Protogène, et sur la peinture à plusieurs enduits, dans Mémoire de littérature, tirés des registres de l'Académie des Inscriptions et Belles-Lettres, depuis l'année MDCCLXXX, jusques et compris l'année MDCCLXXXIV. Tome XLVI. Paris, 1793, pp. 463-76.

[Catalogue Delatour] Premier catalogue des livres, la plupart précieux, du cabinet de feu M. L.-F. Delatour, ancien imprimeur-libraire et secrétaire du roi. Paris: Tilliard Frères et J.-G. Merigot, avril-mai 1808, 80 p.

—- Second catalogue des livres, des ouvrages chinois, tartares, etc., tant manuscrits qu'imprimés, dessins, gravures et peintures à gouache, etc., exécutés à la chine, du cabinet de feu M. L.-F. Delatour, ancien-imprimeur et secrétaire du roi. Paris: Tilliard Frères et J.-G. Merigot, janvier 1810, 185 p.

Catalogue de vente de MM. Burgersdijck et Niermans, Leiden, 1910, vente du 14-23 novembre 1910, 258 p.: Catalogue des bibliothèques de feu M.F.F. $C$. Fischer, docteur en philologie classique et recteur du gymnase réformé à Arnhem, M. F. v. Rijsens, historien et inspecteur des écoles à Alkmaar, M. N. A. Cramer, professeur d'histoire au gymnase à Zwolle, M. R. Oort, pasteur de l'église réformée à Ruurloo avec la bibliothèque importante d'un ancien professeur de droit et plusieurs autres successions.

Catalogue des livres, imprimés et manuscrits, composant la bibliothèque de feu M. Louis-Mathieu Langlès [...] dont la vente se fera le jeudi 24 mars 1825 et jours suivants, 6 heures de relevée, Maison Silvestre, rue des Bons-Enfants, $n^{\circ}$ 30. Paris: J.-S. Merlin, XVIII-558 p.

Catalogue d'une collection de livres précieux et importants provenant pour la plupart de la bibliothèque de feu M. Étienne Quatremère de l'Institut. Rédigé par M. Ch. Halm, conservateur en chef de la Bibliothèque Royale de Munich. Première partie: Numismatique, archéologie, épigraphie, art moderne dont la vente aura lieu à Paris le jeudi 25 novembre 1858 et jours suivants. À sept heures précises du soir, Maison A. Franck, rue Richelieu, 67. Par le ministère de $\mathrm{M}^{\mathrm{e}}$ Boulouze, commissaire-priseur. $52 \mathrm{p}$.

Churchill W. A., Watermarks in paper in Holland, England, France, etc, in the XVII and XVIII centuries and their connection and their inter-connection. Amsterdam: Menno Hetzberger and Co., 1935, 94 p. et CDXXXII pl.

Couvreur M. et D. Viviers, Galland se relit: correction ou censure?, dans Revue belge de philologie et d'histoire 72 (1994), pp. 585-93.

—_, Jacob Spon, à travers un manuscrit inédit de la Bibliothèque Royale de Belgique, dans Jacob Spon: un humaniste lyonnais au XVII siècle, pp. 247-56.

CUPER Gisbert, Lettres de critique, d'histoire, de littérature, etc écrites à divers savans de l'Europe, par feu Monsieur Gisbert Cuper [...] publiées sur les originaux par Monsieur de B**. À Amsterdam, chez Henri de Sauzet et Guillaume Smith, 1742, XXIV-583 p.

Étienne De Byzance, Perì póleōn. Stephanus de Urbibus quem primus Thomas de Pinedo lusitanus: latii jure donabat, et observationibus Scrutinio Variarum Linguarum, ac pracipue Hebraica, Phoenicia, Graca et 
Latina detectis illustrabat, his additce prater ejusdem Stephani Fragmentum Collationes Jacobi Gronovii cum codice Perusino, una cumgemino rerum et verborum indice ad Stephanum et Thoma de Pinedo observationes, Amstelodami: typis J. de Jonge, 1678.

, Ethnikà kat' epitomen Stephani Byzantini Gentilia per epitomen, antehac Perì póleōn, de urbibus, inscripta. Éd. d'Abraham Berkelius. Lugduni Batavorum: apud D. A. Gaesbeeck, 1688.

—- Genuina Stephani Byzantini de urbibus et populis fragmenta. Lugduni in Batavis: apud D. A. Gaesbeeck, 1674.

Fróis L., Traité de Luís Fróis, S. J. (1585) sur les contradictions de mours entre les Européens et les Japonais. Traduit en français par Xavier de Castro et Robert Schrimpf, Paris. Chandeigne, 1993, 189 p.

Galland A., Journal d'Antoine Galland pendant son séjour à Constantinople (1672-1673). Édité par Ch. Schéfer. Paris: E. Leroux, 2 vol. Réimp. anastatique Frankfurt am Main: Institute for the History of Arabic-Islamic Science, 1994.

_- Le Voyage à Smyrne: un manuscrit d'Antoine Galland (1678), contenant Smyrne ancienne et moderne et des extraits du Voyage fait en Levant. Avant-propos d'André Miquel, textes présentés, établis et annotés par Frédéric Bauden. Paris: Éditions Chandeigne (collection Magellane), 2000, 336 p. - Sommaire ou Mémoire chronologique de la vie d'Antoine Galland. Édité par H. Omont dans Journal parisien d'Antoine Galland (v. infra).

_- Voyage fait en Levant. Édition de Cl. Brigault, mémoire dactylographié sous la direction de Fr. Deloffre (Faculté des Lettres de Lyon), 1962.

GAUdRIAUlt R., Filigranes et autres caractéristiques des papiers fabriqués en France aux XVII e et XVIII ${ }^{e}$ siècles. Paris: CNRS Éditions/J. Telford, 1995, $322 \mathrm{p}$. et $150 \mathrm{pl}$.

Gaulmier J., À la découverte du Proche-Orient: Barthélemy d'Herbelot et sa Bibliothèque orientale, dans Bulletin de la Faculté des Lettres de Strasbourg, 48 année, 1 (octobre 1969), pp. 1-6.

Gros DE Boze, Histoire de l'Académie Royale des Inscriptions et Belles-Lettres depuis son établissement, avec les éloges des Académiciens morts depuis son renouvellement. Tome II. Paris: Hippolyte-Louis Guerin, 1740 (pp. 34-49: éloge de Mr. Galland, pp. 50-4: catalogue des ouvrages de M. Galland).

Jacob Spon: un humaniste lyonnais du XVIIe siècle. Catalogue d'une exposition qui s'est tenue à Lyon du 20 octobre au 8 décembre 1993, dont les textes ont été réunis sous la direction de Roland Etienne et Jean-Claude Mossière. Lyon: Bibliothèque Salomon-Reinach, 1993, 326 p.

LAUREns H., Aux sources de l'orientalisme, la «Bibliothèque orientale» de Barthélemi d'Herbelot, Paris, 1978, 103 p.

LEGRAND É., Bibliographie hellénique ou description raisonnée des ouvrages publiés par des Grecs au dix-septième siècle. 5 tomes. Paris, 1894-1903. Réimp. anastatique, Bruxelles: Culture et civilisation, 1963. 
Lyna Fr., Catalogue des manuscrits de la Bibliothèque Royale de Belgique. Tome XI: Histoire de Hollande, mélanges d'histoire, géographie, voyages, itinéraires, expéditions. Bruxelles: Maurice Lamertin, libraire-éditeur, 1927, VIII-320 p.

Madan F., A Summary Catalogue of Western Manuscripts in the Bodleian Library at Oxford. Volume III. Oxford, 1895.

MAY G., Les Mille et une nuits d'Antoine Galland ou le chef-d'œuvre invisible. Paris: PUF, 1986, 247 p.

Miquel-Ravenel J., À la rencontre d'Antoine Galland, premier traducteur des Mille et une nuits, dans Arabica 41 (1994), pp. 147-61.

Omont H., Athènes au XVII'e siècle, dans Revue des Études Grecques 14 (1901), pp. 270-294.

_- Journal parisien d'Antoine Galland (1708-1715), précédé de son autobiographie (1646-1715). Paris (Mémoires de la Société de l'Histoire de Paris et de l'Ile-de-France, t. XLVI), 1919, $156 \mathrm{p}$.

—., Missions archéologiques françaises en Orient aux XVII et XVIII siècles. Vol. II. Paris: Imprimerie nationale, 1902.

, Projets de prise de Constantinople et de fondation d'un empire français d'Orient sous Louis XIV, dans Revue d'histoire diplomatique 7 (1893), pp. 195-246.

PitTon DE TOURnEFort, Relation d'un voyage du Levant fait par ordre du Roy. Tome III. Lyon: Anisson et Posuel, 1717.

REED G., Claude Barbin, libraire de Paris sous le règne de Louis XIV. GenèveParis: Librairie Droz, Centre de recherches d'histoire et de philologie de la IV $^{\text {e }}$ Section de l'École pratique des Hautes Études (VI: Histoire et civilisation du livre, 5), 1974, XI-131 p.

ScIlla A., La vana speculazione disingannata dal senso, lettera risponsiva circa $i$ corpi marini che petrificati si trovano in varij luoghi terrestri [...]. In Napoli: appresso Andrea Colicchia, 1670, [4ff]-168 p., XXVIII pl. et front.

Sommervogel C., A. DE BACKer et A. DE BACKer, Bibliothèque de la Compagnie de Jésus. 11 vol. Bruxelles-Paris, 1890-1932.

VAN DER CRuysse D., Chardin le Persan. Paris: Fayard, 1998, 568 p.

c) Liste des manuscrits cités.

Berlin, Staatsbibliothek Preussischer Kulturbesitz ms. Hamilton 247

Bruxelles, Bibliothèque Royale Albert Ier ms. II 5370

La Haye, Bibliothèque Royale ms. fr. $\mathrm{n}^{\mathrm{o}} 72 \mathrm{H}$

Londres, British Library Add. ms. 22910; Sloane Papers, Dutch copies 130 
Lyon, Bibliothèque municipale

mss. 1720; 1721

Munich, Bayerische Staatsbibliothek

cod. gall. 727; cod. gall. 728; cod. gall. 751

Oxford, Bodleian Library

ms. Smith 46

Paris, Bibliothèque Nationale de France

Cabinet des médailles, archives, dossier de l'année 1682

mss. fonds fr. 6088; 6089; 6130; 6131; 6133; 9360; 14963; 15277-80;

$21942 ; 21946 ; 24277$; n. a. 6833 ; n. a. 11403 ; ms. fonds lat. 17174

Paris, Bibliothèque de l'Arsenal

ms. 2743

\section{Annexe 1}

Bibliothèque municipale de Lyon, ms. 1721, lettre $119^{159}$.

\section{Barbin à Spon.}

«Je voudrois bien Monsieur estre en Estat de pouvoir respondre, a toutes les honnestetes que vous m'avez faites, par la lettre qu'il vous a pleu de m'escrire, mais les Engagemens que j'ay eu et que j'auray peut estre avec Mons ${ }^{\mathrm{r}}$ Guillet, me necessite a vous remercier seullement de vos offres, et vous temoigner que j'en auray toute ma vie de la recognoissance. Vous savez Monsieur qu'il est des biens seances dont on ne peut se dispenser jamais, et particulierement quand il s'agit de l'Espoir, et quelque indifférence que l'on affecte d'avoir dans ces sortes de critiques. neantmoins le Coeur est toujours preoccupé, et très souvent l'on conserve du resentiment contre ceux qui ont pressé leur ministere a les rendre publiques, quoy qu'en effet les libraires en deussent estre exempt. Je say bien que sy j'avois presenty M. G. qu'il donneroit les mains aux acomodemens pour ne point prejudicier a mes suretez, je croy mesme qu'il luy seroit assez indifferant que ce fut moy aussy bien qu'un autre, puisque l'ouvrage deviendra public, mais enfin il $\mathrm{y}$ a toujours quelques choses a redire, et pour ne point tomber dans toutes ces disensions je m'en tiens a vous en tenir compte et vous offrir mes services en toutes autres ocasions. pour de vos Miscellanea, quand vous serez en Estat d'en pouvoir disposer comme il n'interessent personne avec lesquels j'aye des liaisons // vous me trouverez toujours en disposition d'en traiter de facon ou d'autre aussy bien que de tous les autres ouvrages que vous donnerez au public, car enfin Mon-

159 Une transcription en français moderne de cette lettre ainsi que de celle figurant à l'annexe 5 avait déjà été donnée par G. Reed, op. cit. Nous avons jugé bon de les reproduire ici, en respectant l'orthographe de l'époque, étant donné leur importance pour une meilleure compréhension de certains aspects de notre texte. 
sieur il y a peu de personnes qui vous estime plus que moy, et cela soit dit seullement en passant et sans consequence, pour la relation de Samos Patmos \&c de M. Gallant, j'en pourois traiter si je voyais ce que c'est, non pas dans le dessein d'augmenter l'archipel que j'ay imprimé car je ne l'estime pas assez pour lui donner des Ilustrations, mais je le pourois joindre avec sa Smirne ancienne et nouvelle qu'il m'a laissé, aussy sy vous trouvez apropos de l'Envoyer a M. Vaillant quand je l'auray veu quoy que je ne sois pas un Grand connoisseur j'auray neantmoins bien tost fait, pour l'histoire de Geneve, il est difficile d'accepter les propositions des 40 pistoles sans voir Les Choses auparavant, ou du moins, un petit memoire succint du desseing et de l'oeconomie de l'ouvrage, afin de connoistre les Choses pour y fixer un prix. ce n'est pas Monsieur que vostre reputation, ne soit interessée dans ces difficultez là, et que vous ne me fassiez assez de Grace en me l'offrant, mais la Crainte que dans ces sortes d'ouvrages il n'y entre de la religion, ou bien que les advantages ne tournant que du costé des Citoyens quy en ce cas là deviendroit un livre particulier, ne fut pas un livre propre à tout le monde, cela disje cause toute ceste suspension quy finira quand vous Le voudrez. Je suis bien obligé à Monsieur du Four de m'avoir menagé l'honneur de vostre connoissance comme il a bien de la bonté pour moy // il a esté bien aise de m'en faire resentir les effets, et j'ose vous dire Monsieur qu'il m'a pris par l'endroit le plus sensible, car en effet je conte pour beaucoup le bien d'estre connu de vous, et quoy que je luy soit aquis autant qu'on le peut estre, je sais neantmoings, que je le voudrois estre davantage par le plaisir qu'il m'a fait, Je vous demende Excuse de ceste digresion que je n'ay pu m'empecher de faire et j'atendray avec Impatiance les ocasions de vous temoigner que je suis veritablement et avec respect

Monsieur

Votre tres humble serviteur Barbin ce $20^{\mathrm{e}}$ Juin $1679 »$.

\begin{abstract}
Annexe 2
Bibliothèque municipale de Lyon, ms. 1720, lettre 64.

Charpentier à Spon

«Monsieur,

Je vous rends très humbles graces du beau Livre que vous m'avez fait l'honneur de m'envoyer et que je n'ay receu que depuis quatre ou cinc jours. Quelque temps auparavant j'en avois trouvé un pareil entre les mains de Monsieur l'Abbé Huet sous precepteur de Monseigneur le Dauphin a qui le R. P. De Lachaise en avoit fait present. je vous puis dire que vous fustes le sujet de nostre entretetien durant une demye apres-disnée que nous passasmes ensemble dans le
\end{abstract}


Jardin des Tuilleries. Il l'avoit leu avec cette avidité dévorante qu'excite ordinairement un ouvrage plein d'agrément et de solidités comme le vostre, et j'en fais très résolution d'en faire mes delices et le compagnon de toutes mes promenades durant l'esté. Je vous scay bon gré Monsieur de ne vous tenir pas tousjours dans le cabinet et d'aller visiter sur les lieux mesmes les matieres de nostre curiosité. C'est de la façon qu'ont estudié les plus celebres autheurs de l'Antiquité comme Herodote Xenophon, Diodore Sicilien Pausanias et quelques autres. Mais il n'est pas permis a tout le monde // de suivre une inclination si noble ni d'en profiter. Nous avons veu tant de voyageurs qui nous ont debité les choses avec obscurité et confusion et quelques uns mesmes contre leur conscience. Il y en a d'autres qui ne sont gueres moins a craindre et surtout ceux qui donnent trop d'estendue a leurs conjectures et qui ayment mieux publier leurs resveries que de demeurer dans un honeste silence quand ils n'ont rien d'asseuré a dire. Je me propose comme un grand plaisir Monsieur de lire quelque jour vos scavantes observations sur tant de matieres curieuses contenues dans une fueille imprimée que m'a envoyée Monsieur Dufour. Pour remplir dignement toutes ces promesses comme vous le ferez sans doute il ne faut pas voir de loin les choses des Anciens. Il faut se transporter jusques dans leur siecle ou pour mieux dire les faire revivre dans le nostre. Il faut faire parler le bronze et les marbres et tirer du fonds des sepulchres une idée vivante des choses qui ne sont plus. Tous ces miracles s'achevront par vostre profonde erudition et j'espere que vous nous vengerez de tant de visions chimeriques dont les Critiques modernes ont abusé nostre credulité. // A l'esgard des livres dont vous desirez obtenir le Privilège, je donneray a Monsieur Vaillant mon attestation quand il le desirera. J'ay veu autrefois a Paris le traducteur du petit manuscrit turc et j'eusse este bien ayse de luy pouvoir ayder dans sa fortune qui me paroissoit avoir besoin de secours. Voyez la sottisse de nos Libraires: Monsieur Vaillant m'a dit qu'on avoit laissé celui ci entre les mains d'un abbe affin d'y inserer des intrigues amoureuses. C'est a dire affin de corrompre la verité et faire une fable ridicule d'une histoire serieuse. rien n'est plus condemnable a ma fantaisie que ceste maniere d'escrire qui bien loin d'obtenir la permission d'Imprimer meriteroit mesme quelque punition. Quand je scauray Monsieur ce que je pourray faire pour vostre service je vous supplie d'estre très persuadé que je n'y manqueray jamais et que je compteray pour une faveur singuliere quand vous me voudrez bien fournir les occasions. Je suis de tout mon cœur

Monsieur

[P. S.] on vient de recevoir nouvelle que Gand es rendu.

vostre tres humble et tres obeissant serviteur. Charpentier» 


\begin{abstract}
Annexe 3
Bibliothèque Royale Albert Ier (Bruxelles), ms. II 5359: JacquesPaul Babin, Relation de l'Isle de Tines contenue dans une lettre à Mons $^{r} * * * *$.

$\left[\begin{array}{ll}f^{\circ} & 185\end{array}\right]$ «Monsieur, j'ay différé de vous envoyer la Relation de l'Isle de Tines que vous m'aviez demandée, en partie à cause des grandes occupations que j'ay icy pour l'instruction \& le bien spirituel de cette petite chrestienté environnée du pays des infidelles, \& en partie pour découvrir avec plus de loisir les raretez de ce lieu, et vous en pouvoir faire une description plus exacte. Je n'avois encore rien remarqué lorsque vostre lettre me fut rendue, et je ne jugeois pas mesme qu'il y eust icy rien de curieux; mais depuis ce temps là, j'ay esté prescher dans la pluspart des villages qui sont habités des Latins ou des Grecs, et j'ay eu par ce moyen l'occasion de visiter toute l'Isle, et de voir s'il y avoit

[ $\left.f^{\circ} 196\right]$ «Tous ces employs m'ont empesché d'achever cette relation que vous m'avez demandée depuis deux années, mais elle ne laissera pas d'estre nouvelle pour vous et de vous estre une preuve de la passion que j'ay à contribuer à vostre curiosité et à vous protester que je suis toujours
\end{abstract} quelque chose digne de vostre curiosité».

$$
\text { [...] }
$$

Vostre très humble et très obéissant serviteur Jacques Paul Babin de la Compagnie de Jésus

à Tines ce 21 (raturé au profit de 3) Avril 1679»

\title{
Annexe 4
}

Bibliothèque Royale Albert Ier (Bruxelles), ms. II 5359: Estat présent des Isles de Samos, Nicarie, Patmos et du Mont Athos par Joseph Georgerine, Archevesque de Samos. Traduit du grec vulgaire en françois par Antoine Galland.

Préface du traducteur (ff. 139-140)

«La passion toute particuliere que j'ai de connoistre les Isles de l'Archipel fit qu'a l'arrivée de $\mathrm{M}^{\mathrm{r}}$ l'Archevesque de Samos a Paris, je l'engageai a composer en grec vulgaire une relation de ces trois Isles et du Mont Athos, ou il a pris l'habit de caloier et demeurè six années. Je la mis en mesme temps en nostre 
langue a mesure qu'il m'en fournissoit les cahiers. Mais dans le temps que j'allois prendre des precautions pour faire imprimer ma version, il passa en Angleterre et l'emporta avec luy en me laissant l'original. Et comme il me pria de ne point faire imprimer la seconde version que j'en pourrois entreprendre, que je n'eusse appris qu'il eust fait traduire et imprimer en Anglois, l'amitiè que je luy portois fit que je luy tins la parole que je luy en donnai, ne voulant point porter de prejudice aux veües qu'il pourroit avoir, et luy laissai la libertè toute entiere d'en disposer comme il luy plairoit.

Une année s'ecoula sans que j'apprisse // ce qu'il en avoit fait, et je fis un second voiage en Levant de dix a onze mois sans en avoir autre nouvelle a mon retour, jusqu'a ce qu'estant a Marseille dans l'attente d'un embarquement pour retourner une troisieme fois en Turquie, j'en reçois enfin l'edition en Anglois faite a Londre il y a près d'une année. Tout privè que je suis de l'original grec, je n'ai point laissè d'en entreprendre une nouvelle traduction de la langue Angloise. J'avoüerai que je ne la possede pas encore trop bien, et que je n'en serois pas venu a bout, si je n'avois eu de fortes idées de l'original. De sorte que bien que ce François ait estè fait sur l'Anglois, je ne fais point difficultè de dire que c'est proprement une version sur le grec vulgaire que la connoissance confuse de la langue angloise m'a remis dans la mémoire.

J'avois eu dessein de ramasser dans les autheurs anciens ce que j'aurois trouvè de remarquable touchant ces lieux pour en faire un Estat Ancien et Moderne. il y auroit asseurément eu de quoi s'estendre au sujet de Samos, non seulement a cause que les Autheurs en ont parlè amplement, mais encore, parce qu'il y a lieu de s'estendre au sujet d'un grand nombre de medailles des Empereurs Romains qui y ont estè frappées. //

Mais estant sur le point de m'éloigner de la France pour quelques années, je n'ai point voulu priver plus longtemps les personnes curieuses des relations estrangeres du plaisir que celle ci leur pourra donner. La reception favorable qu'ils en feront m'obligera peut estre de leur communiquer a mon retour, ce que j'en aurai decouvert de nouveau, particulierement touchant l'Isle de Samos et le Mont Athos.

Pour ce qui est de Patmos ou j'ay estè et ou je fis connoissance avec $\mathbf{M}^{\mathrm{r}}$ l'Archevesque de Samos, je ne pense pas que j'y puisse adjouter rien de plus particulier. Il en rapporte tout ce que j'en aurois pu dire avec des singularités dont je n'ai pu m'instruire en huict jours de temps que j'y sejournai seulement. L'exactitude que je connois qu'il y a apportée me persuade qu'il n'est pas moins sincere dans la description de Samos, de Nicarie et du Mont Athos, et qu'il a obmis peu de chose de ce qui s'en pouvoit dire, outre que j'ai souvent entendu faire le recit des mesmes choses a des personnes qui en estoient informès.

Quoi qu'il en soit les lecteurs peuvent estre asseurès de la fidelitè de l'autheur qui n'a point eu d'autre but que de dire la veritè, qu'une longue experience et un long sejour sur les lieux luy ont apprise. //

J'apprens qu'apres avoir veu l'Italie, la France et l'Angleterre, il doit bientost se rendre en ceste ville de Marseille pour retourner dans l'Archipel. Je suis ravi 
de l'occasion qui se presente de m'abboucher encor une fois avec luy pour le prier de travailler sur d'autres Isles qui seront de sa connoissance, et de m'aider en cela au dessein que j'ay sur une description generale de tout l'Archipel.

Je sçai qu'il y a des Autheurs qui en ont desja traitté, mais je sçai aussi qu'ils n'ont point tout dit et qu'il y a apres eux de quoi occuper la plume d'un ecrivain qui voudra particulariser les choses dans un plus grand detail. C'est pourquoi cela ne m'empechera point de continüer les remarques que j'ay desja commencées pour ce projet, et de faire tout ce que je pourrai pour visiter moi mesme les Isles les plus considerables et les plus dignes d'estre connües des personnes qui aiment la geographie meslée d'histoire.

Cependant recevès avec faveur ce que je vous offre presentement, et accompagnès de vos vœux les bonnes intentions que j'ay de vous offrir un jour des choses qui meriteront mieux vostre approbation».

\section{Annexe 5}

Bibliothèque municipale de Lyon, ms. 1721, lettre 122.

\section{Barbin à Spon}

«Je crains bien Monsieur qu en vous expliquant mes petits sentiments sur les interez de M. Guillet, je naye glissé quelques choses dans ma lettre quy ait mal respondu aux offres honnestes que vous m'aviez faites, car a vous dire vray vous $\mathrm{m}$ avez parut tres mescontent par celle quil vous a plut de $\mathrm{m}$ escrire, cependant Monsieur J oseray vous dire avec tout le respect que je vous doit que le cœur et les intentions $\mathrm{n}$ ont nul part aux fautes que je pourois avoir faites en vous exposant mes scrupules, et sy je vous ay parut avoir un peu trop de délicatesse dans des choses ou 1 on doit avoir de tres grandes indifferances, ne 1 atribuez s il vous plaist qu a mon seul desfaut de lumierre, en tout cas je vous demendes excuses en vous assurant que je vous en feray telle satisfaction qu il vous plaira.

Je vous remercie Monsieur de 1 offre que vous me faites de cette petite relation du P. Babin pour joindre a la Smirne de M. Gallant, comme la diversite plaist dans les livres et sur tout dans les relations je crois que cela ne sera pas un petit ornement au livre puis quelle a vostre aprobation, pour les conditions je les acceptes, et je me feray un tres grand plaisir de vous envoyer mes livres nounvaux en eschanges puis qu'en $\mathrm{m}$ aquitant de mes debtes je satisferay plainement mon inclination. Il vous suffira seullement de me marquer ceux de vostre gout pour ne vous rien envoyer d'inutille et de me croire en atendant responce

Monsieur

vostre tres humble et tres obeissant serviteur Barbin.

ce 20 juillet 1679 » 


\section{Annexe 6}

\section{hiviremu}

$\mathrm{N}^{\circ} 1$ : écriture de Galland (corrections), Smyrne ancienne et moderne, $f^{\circ} 5^{\mathrm{v}}$.

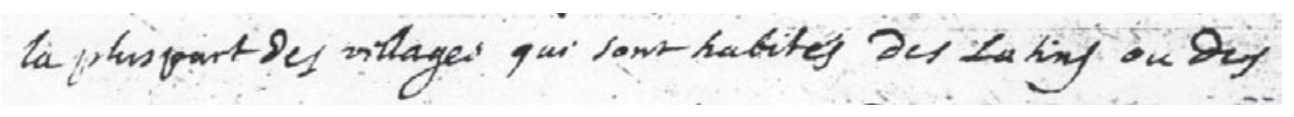

$\mathrm{N}^{\circ}$ 2: écriture de Spon, Relation de l'Isle de Tines, $f^{\circ} 185$.

\section{honitk}

$\mathrm{N}^{\circ}$ 3: écriture de Galland pour la copie de la Smyrne ancienne et moderne, $f^{\circ} 5^{\mathrm{v}}$.

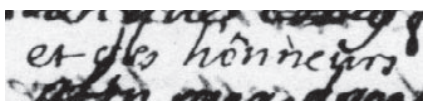

$\mathrm{N}^{\circ}$ 4: écriture de Galland (corrections), Voyage fait en Levant

(Munich, cod. gall. 727, p. 1).

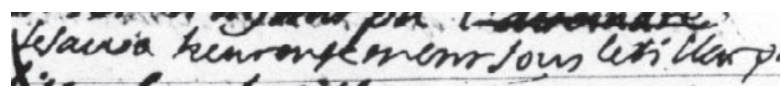

$\mathrm{N}^{\circ}$ 5: écriture de Galland (corrections), Voyage fait en Levant (Munich, cod. gall. 727, p. 56). 


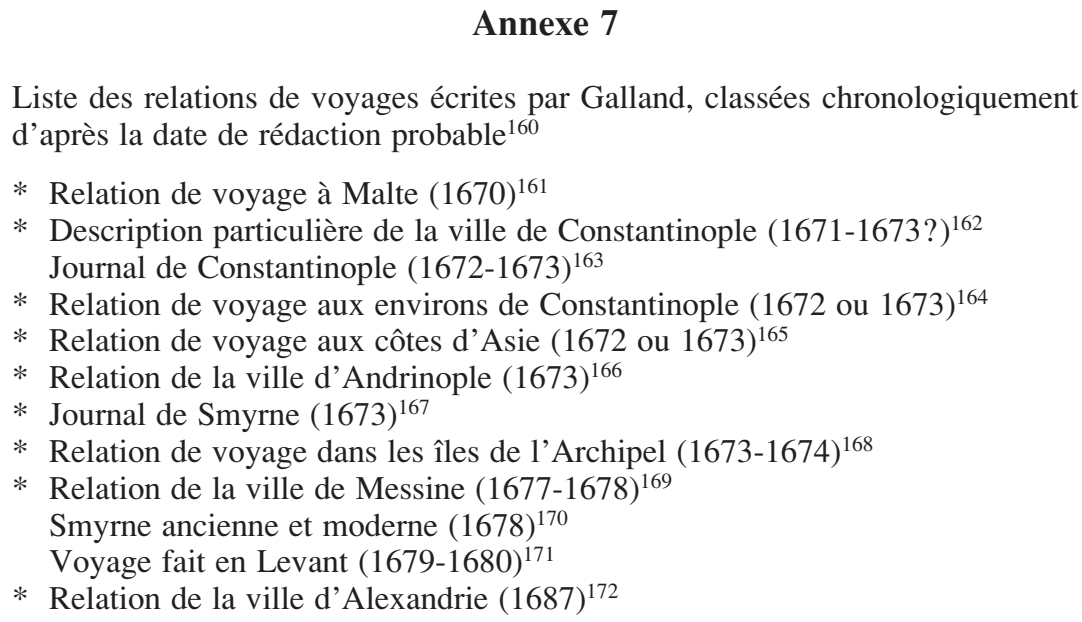

${ }^{160}$ L'astérisque indique que la relation est considérée comme perdue.

161 Mention dans une lettre adressée à Huet, le 25/02/1701. V. Abdel-Halim, Correspondance, pp. 362-3.

162 Mention par Gros de Boze, Histoire de l'Académie Royale des Inscriptions et Belles-Lettres depuis son établissement, avec les éloges des Académiciens morts depuis son renouvellement. Tome II, pp. 46 et 54 .

163 Conservé à la BnF, fonds fr., 6088-6089.

164 Mention dans la lettre adressée à Huet citée supra.

165 Ibidem.

166 Ibidem. Copies envoyées à Baudequin et Petitpied. V. Abdel-Halim, Correspondance, pp. 70 et 72.

167 Annoncé dans une lettre adressée à Petitpied en 1673. V. op.cit., pp. 108-9.

168 On en retrouvera une partie dans le Mémoire des antiquités qui restent encore de notre temps dans l'Archipel et dans la Grèce.

169 Mention dans la Smyrne ancienne et moderne et dans la lettre à Huet citée supra.

170 Conservée à la Bibliothèque Royale Albert Ier de Bruxelles, ms. II 5359.

171 Conservé à la Bayerische Staatsbibliothek de Munich, cod. gall. 727-728.

172 Mention dans la lettre adressée à Huet citée supra où il indique que la minute qu'il en avait gardée fut détruite à cause du tremblement de terre qui survint à Smyrne en 1688, et que la copie envoyée à Rainssant ne fut pas retrouvée à sa mort. 